\title{
Expanding access to integrated family planning intervention packages for married adolescent girls in urban slums of Dhaka, Bangladesh
}

Fauzia Akhter Huda

Hassan Rushekh Mahmood

Sadia Afrin

Anisuddin Ahmed

Nafis Al Haque

See next page for additional authors

Follow this and additional works at: https://knowledgecommons.popcouncil.org/departments_sbsr-rh

Part of the Demography, Population, and Ecology Commons, Family, Life Course, and Society Commons, Gender and Sexuality Commons, Inequality and Stratification Commons, International Public Health Commons, Maternal and Child Health Commons, and the Women's Health Commons How does access to this work benefit you? Let us know!

\section{Recommended Citation}

Akhter Huda, Fauzia, Hassan Rushekh Mahmood, Sadia Afrin, Anisuddin Ahmed, Nafis Al Haque, and Bidhan Krishna Sarker. 2017. "Expanding access to integrated family planning intervention packages for married adolescent girls in urban slums of Dhaka, Bangladesh," STEP UP Research Report. Dhaka: icddr.b. 


\section{Authors}

Fauzia Akhter Huda, Hassan Rushekh Mahmood, Sadia Afrin, Anisuddin Ahmed, Nafis Al Haque, and Bidhan Krishna Sarker 


\section{STEP}

STRENGTHENING EVIDENCE FOR PROGRAMMING ON UNINTENDED

BANGLADESH

RESEARCH REPORT

JUNE 2017

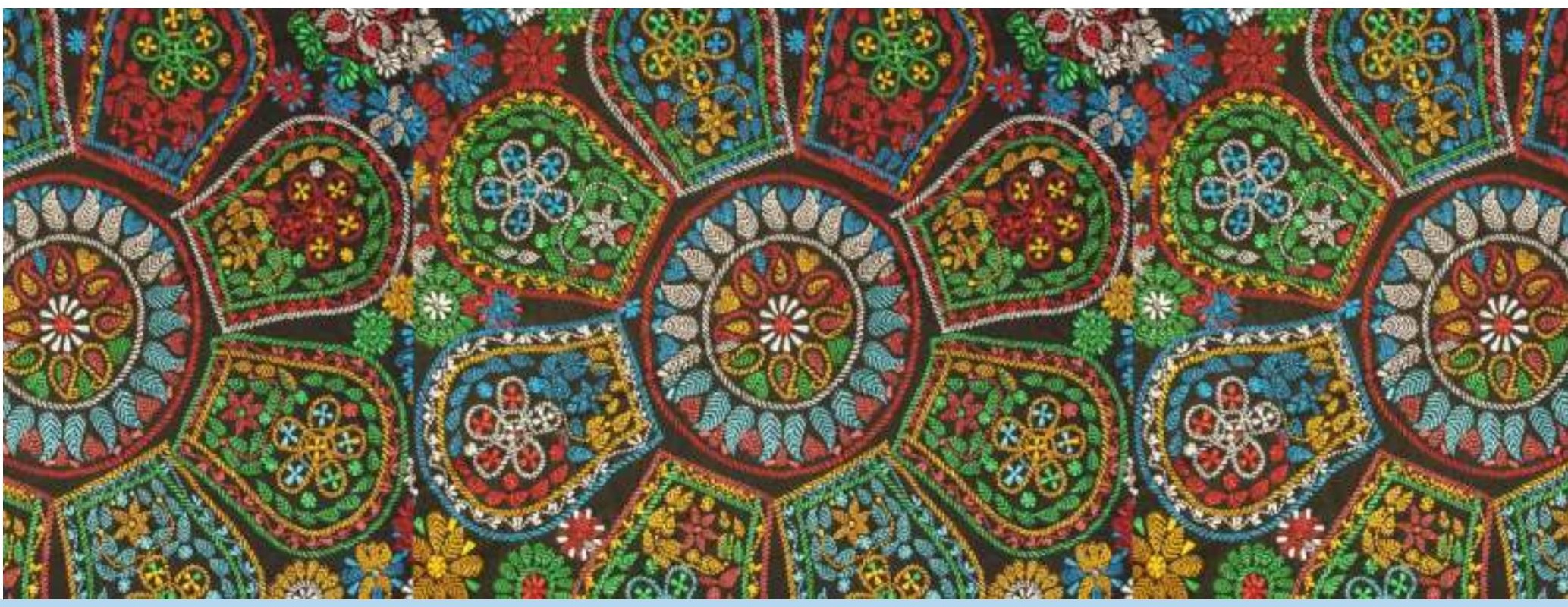

Expanding Access to Integrated Family Planning Intervention Packages for Married Adolescent Girls in Urban Slums of Dhaka, Bangladesh

FAUZIA AKHTER HUDA, HASSAN RUSHEKH MAHMOOD, SADIA AFRIN, FAISAL AHMMED, ANISUDDIN AHMED, NAFIS AL HAQUE, ANADIL ALAM, AND BIDHAN KRISHNA SARKER 


\section{Expanding Access to Integrated Family Planning Intervention Packages for Married Adolescent Girls in Urban Slums of Dhaka, Bangladesh}

FAUZIA AKHTER HUDA, HASSAN RUSHEKH MAHMOOD, SADIA AFRIN, FAISAL AHMMED, ANISUDDIN AHMED,

NAFIS AL HAQUE, ANADIL ALAM AND BIDHAN KRISHNA SARKER

Maternal and Child Health Division (MCHD) icddr,b, Dhaka, Bangladesh

STEP UP RESEARCH REPORT

JUNE 2017

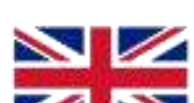

Ukaid 
The STEP UP (Strengthening Evidence for Programming on Unintended Pregnancy) Research Programme Consortium generates policy-relevant research to promote an evidence-based approach for improving access to family planning and safe abortion. STEP UP focuses its activities in five countries: Bangladesh, Ghana, India, Kenya and Senegal. STEP UP is coordinated by the Population Council in partnership with the African Population and Health Research Center; icddr,b; the London School of Hygiene and Tropical Medicine; and Marie Stopes International. STEP UP is funded by UKaid from the UK Government. www.stepup.popcouncil.org

\section{(5) icddr,b}

icddr,b is a Bangladesh-based international health research institute that strives to solve key public health problems through high-quality scientific research and innovation. Policy-makers and practitioners utilize our evidence and expertise to improve health outcomes and prevent premature death and disability worldwide. Established more than 50 years ago, we continue to provide life-saving services to the people of Bangladesh, and to nurture the next generation of global health leaders. www.icddrb.org

\section{- POPUlation \\ COUNCIL \\ Ideas. Evidence. Impact.}

The Population Council confronts critical health and development issues-from stopping the spread of HIV to improving reproductive health and ensuring that young people lead full and productive lives. Through biomedical, social science, and public health research in 50 countries, we work with our partners to deliver solutions that lead to more effective policies, programs, and technologies that improve lives around the world. Established in 1952 and headquartered in New York, the Council is a nongovernmental, non-profit organization governed by an international board of trustees. www.popcouncil.org

Suggested citation: Huda FA; Mahmood HR; Afrin S; Ahmmed F; Ahmed A; Haque NA; Alam A; and Sarker BK. 2017. "Expanding Access to Integrated Family Planning Intervention Packages for Married Adolescent Girls in Urban Slums of Dhaka, Bangladesh" STEP UP Research Report. Dhaka: icddr,b.

\section{(c) 2017 icddr,b.}

Please address any inquiries about STEP UP to the RPC co-directors:

Harriet Birungi, hbirungi@popcouncil.org

Esther Lwanga, elwanga@popocouncil.org

Funded by

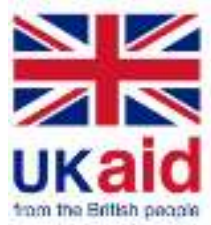




\section{CONTENTS}

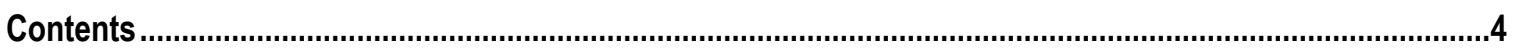

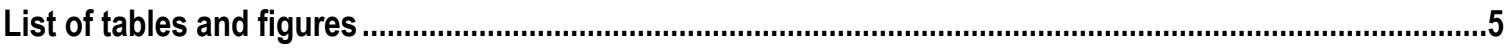

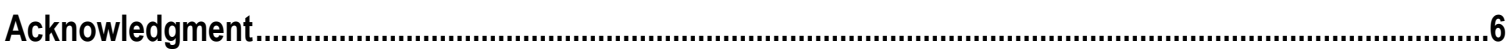

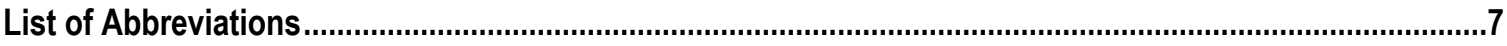

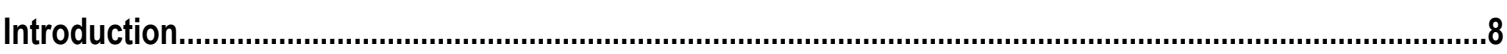

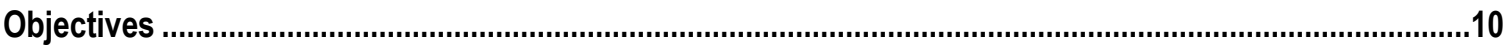

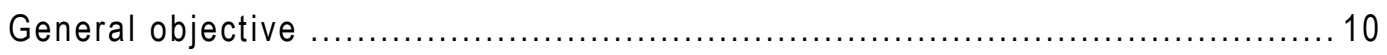

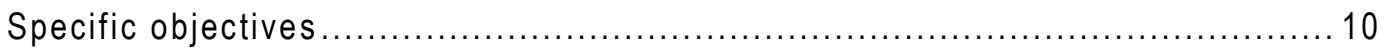

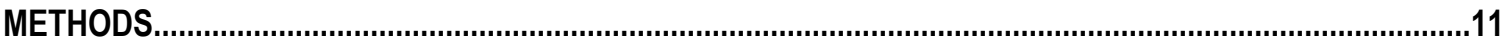

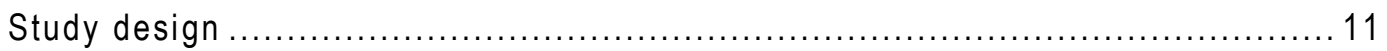

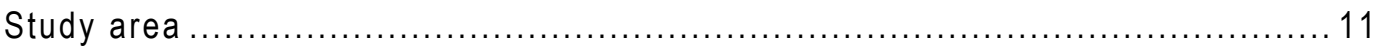

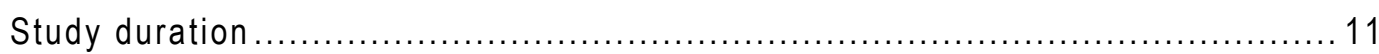

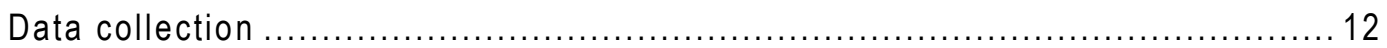

Brief description of the intervention components ................................ 13

Field implementation team members ......................................... 18

Process documentation ............................................................... 18

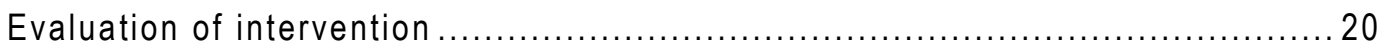

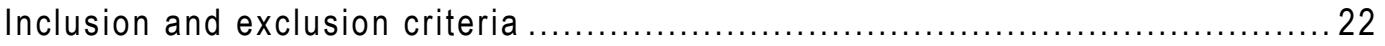

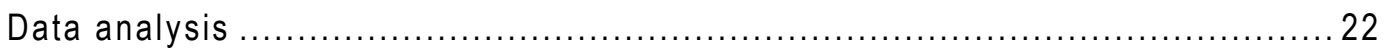

Ethical considerations ................................................................ 23

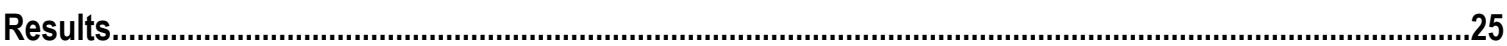

Socio-demographic characteristics of community based survey respondents .....2 25

Socio-demographic characteristics of the qualitative interview respondents ...... 27

Married adolescent girls' club .................................................... 28

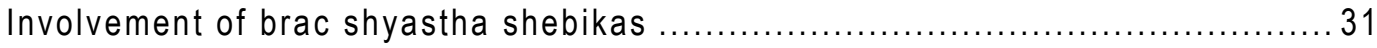

Marriage registrars' role in delivering family planning messages .................... 34

Knowledge and perception of married adolescent girls about early marriage, early

pregnancy, birth spacing, and FP method use ...................................... 38

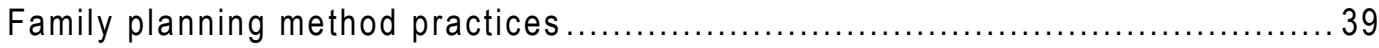

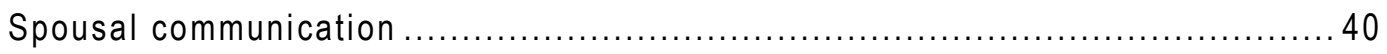

Knowledge on potential consequences of early pregnancy ......................... 41

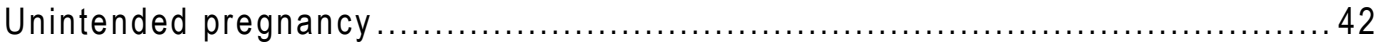

Unmet need for family planning .................................................. 44

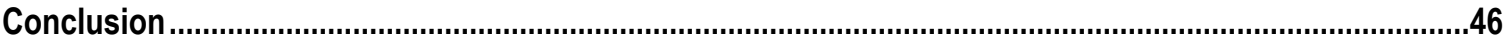

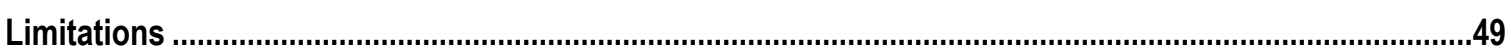

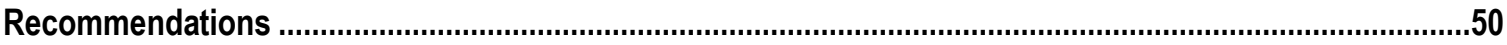

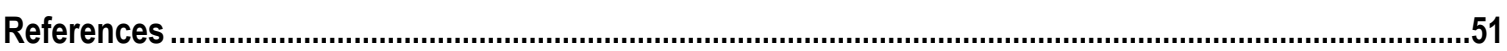

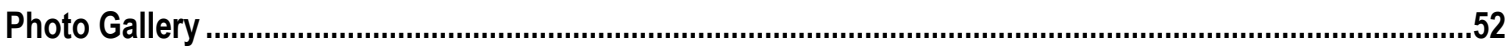




\section{LIST OF TABLES AND FIGURES}

\section{TABLES}

Table 1: Percent distribution of respondents' socio-demographic characteristics by intervention and comparison areas.

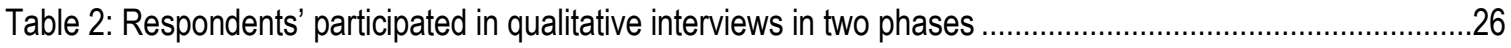

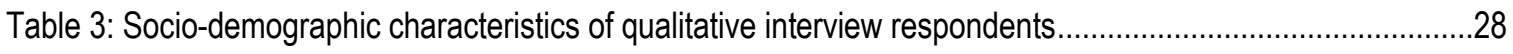

Table 4: Club attendance of respondents' and their feedback on club activities .............................................29

Table 5: Respondents' feedback on Shyastha Shebikas' visit by intervention and comparison areas...................32

Table 6: Respondents' knowledge and perception on early marriage, early pregnnacy, and birth spacing by

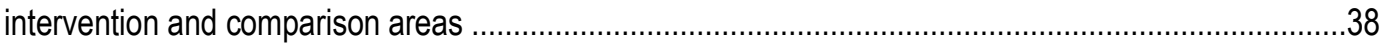

Table 7: Family planning method practice of respondents' by intervention and comparison areas........................39

Table 8: Spousal communication among respondents' by intervention and comparison areas ............................40

Table 9: Respondents' knowledge on potential consequences of early pregnancy by intervention and comparison

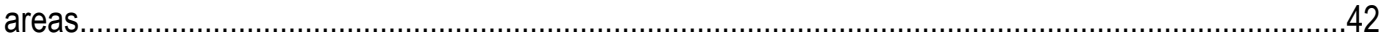

Table 10: Pregnancy intention (last/current) of respondents' by intervention and comparison areas ...................42

Table 11: Percent distribution of respondents' unmet need for FP by socio-demographic characteristics and by intervention and comparison areas

\section{FIGURES}

Figure 1: Family planning pocket book .15

Figure 2: Referral form used by Shyastha Shebikas for promotion of LARC .....................................................17

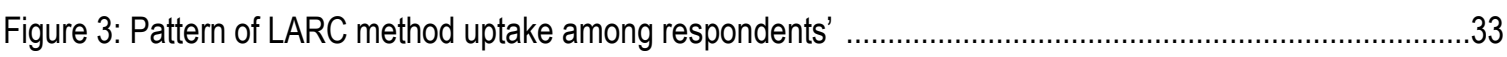

Figure 4: Percent distribution of respondents' by major causes of unintended pregnancy by intervention and comparison area 


\section{ACKNOWLEDGMENT}

We acknowledge support from the STEP UP (Strengthening Evidence for Programming on Unintended

Pregnancy) Research Programme Consortium under which this research protocol was implemented. STEP

UP was funded by UKaid from the Department for International Development (DFID), grant number

SR1111D-6. icddr,b acknowledges with gratitude the commitment of UKaid to its research efforts.

icddr,b is also grateful to the Governments of Bangladesh, Canada, Sweden and the UK for providing core/unrestricted support. 


\section{LIST OF ABBREVIATIONS}

B. A. : Bachelor of Arts

BCC : Behaviour Change Communication

BDHS : Bangladesh Demographic Health Survey

CPR : Contraceptive Prevalence Rate

DGFP : Directorate General of Family Planning

ERC : Ethical Review Committee

FGD : Focus Group Discussion

FP : Family Planning

FRA : Field Research Assistant

FRM : Field Research Manager

FRS : Field Research Supervisor

IDI : Key Informant Interview

IRB : Institutional Review Board

IUD : Intra Uterine Device

KII : Key Informant Interviews

LARC : Long Acting Reversible Contraceptive

MR : Menstrual Regulation

NGO : Non-Governmental Organization

SS : Shasthya Shebika

UP : Unintended Pregnancy 


\section{INTRODUCTION}

In Bangladesh, early marriage and childbearing has led to an adolescent fertility rate that is among the highest in the world. The average age of marriage for girls is 14-15 years in the country although the legal age of marriage is 18 years [1]. There is still very strong social and family pressure on girls to marry at an early age and to prove their fertility soon after marriage. In addition to early marriage, lack of accessible family planning and reproductive health services also contributes to early childbearing.

The Bangladesh Demographic and Health Survey (BDHS) 2014 showed that 1 in 5 births in girls aged less than 20 years were unintended, with more than $98 \%$ of the unintended births being mistimed (wanted later) and $0.2 \%$ being unwanted [1]. Estimates from the BDHS 2014 further showed that 15.2\% of currently married girls aged between 15-19 years in the urban areas of the country had an unmet need for family planning (FP), with $14.7 \%$ having unmet need for spacing births while $0.5 \%$ had unmet need for limiting births. In addition, $33.9 \%$ of currently married girls of this age group had ever heard of menstrual regulation (MR), although 3.2\% had used MR services [1]. Collectively, these factors contribute to the high rate of unintended pregnancy among married adolescent girls.

Early pregnancies are more likely to be unwanted and are also associated with adverse health, social, and economic consequences. Evidence shows that adolescent pregnancy is correlated with pregnancyrelated complications, preterm delivery, delivery of low birth weight babies, and spousal violence [2]. The broader social consequences of early pregnancy include lower educational attainment, limited ability to become involved in income generating activities, high overall fertility rates, and marital and family difficulties [3]. Adolescents are a particularly vulnerable group, both in terms of early childbearing and unintended pregnancy, and the context in which they live influences that vulnerability. A particularly vulnerable group is married adolescent girls residing in urban slums. Evidence shows that married girls aged 15-19 from slums are almost twice more likely to be mothers as girls from non-slum areas [4].

In 2013, a formative study was conducted among the married adolescent girls in urban slums of Dhaka, Bangladesh, showed that more than half of the pregnancies (53\%) among them were unintended, (52.2\% were mistimed while $0.4 \%$ were unwanted) [5]. The prevalence of unintended pregnancies was more than two times higher among married adolescent girls in the slums than among a similar group of adolescent girls in non-slum areas of Bangladesh (24\% of the births to married adolescent girls aged 15-19 years in these settings were unintended).

Unintended pregnancy among married adolescent girls in the slums was largely due to non-use or discontinuation in the use of FP methods. In particular, 15\% of married adolescent girls in the slums 
had never used FP methods while $27 \%$ had discontinued its use [5]. Non-use and discontinuation of methods were largely due to user-related factors including, irregular use of a method, being unaware of available methods, fear of side effects, method failure, pressure from relatives (mostly husbands and mothers-in-law) to have children, lack of spousal communication, switching methods, and wrong calculation of the safe period [5]. Those who experienced unintended pregnancy were less likely to be aware of family planning before they got married compared to those with intended pregnancies [5].

Furthermore, the prevalence of contraceptive use has been consistently lower among urban slum dwellers than among the non-slum population. Also, door to door services for distributing FP methods as well as counselling and motivational activities for promoting contraception use was very poor in City Corporation areas [6]. In order to reduce unintended pregnancy, the government of Bangladesh has set some goals to increase the contraceptive prevalence rate $(C P R)$, reducing discontinuation/dropout rate of temporary contraceptive methods (oral pills, condoms and injectables), strengthening domiciliary services, providing adolescent reproductive health care services, reducing early marriage, adolescent pregnancy and unsafe abortion as well as unmet need for FP for eligible couples [6].

Government priorities suggest that health education on family planning services is needed to promote awareness and the consistent use of contraceptives for birth spacing among married adolescent girls in urban slums in order to reduce the high levels of unintended pregnancy [6].

The findings also point to the need to improve counselling on FP for adolescent girls and their spouses in order to clear some of the barriers in using family planning services, such as misconceptions and fear of side effects, and to ensure appropriate timing and consistent use of contraceptives [6].

Interventions with FP services should target specific groups, such as participation/support of spouses of adolescent girls, newlywed adolescents, and adolescents who want to space births and who have reached their ideal family size. Interventions that expand access to FP information and services for these girls can help reduce the overall burden of unmet need and unintended pregnancies [5].

Considering the high level of unintended pregnancy and unmet need for family planning among the married adolescent girls living in urban slums, this research project was implemented with an aim to reduce the prevalence of unintended pregnancy and unmet need for family planning (FP) among married adolescent girls living in urban slums of Dhaka, Bangladesh. 


\section{OBJECTIVES}

\section{GENERAL OBJECTIVE}

To reduce the prevalence of unintended pregnancy and unmet need for family planning (FP) among married adolescent girls aged $14-19$ years in urban slums of Dhaka, Bangladesh.

\section{SPECIFIC OBJECTIVES}

1. To test the acceptability and feasibility of formation of a club to expand access to FP information and services to the married adolescent girls.

2. To test the acceptability and feasibility of strengthening the capacity of brac ${ }^{1}$ community health volunteers (Shyastha Shebikas ${ }^{2}$ ) in promoting the uptake of long-acting reversible contraceptives (LARC) among married adolescent girls.

3. To test the acceptability and feasibility of involving marriage registrars' (Muslim, Hindu and Christian marriage registrars) in providing FP information to the newly wed couples at the time of marriage registration.

4. To assess the combined effect of the interventions (involvement of marriage registrars, formation of married adolescent girls clubs, and involvement of brac Shasthya Shebikas on reducing unintended pregnancy and unmet need for FP among married adolescent girls living in urban slums of Dhaka, Bangladesh.

\footnotetext{
1 brac has been delivering basic maternal, neonatal and child health $(\mathrm{MNCH})$ and family planning services through a community based health intervention under its Essential Health Care (EHC) Program, in selected urban slums of several city corporations and selected municipalities including Dhaka in Bangladesh. Since 2007, this community based health program known as Manoshi has been working to reduce maternal and child mortality in urban slums of Bangladesh by proving normal safe delivery services through its birthing huts at the community level.

${ }_{2}^{2}$ Family Planning (FP) is one of the integrated components of brac's Manoshi programme and brac has been implementing a few approaches among the eligible couples, women, family members and community groups to promote FP in addition to maternal, neonatal and child health care. Manoshi has community health volunteers (Shasthya Shebika) who are directly involved in FP services.
} 


\section{METHODS}

\section{STUDY DESIGN}

This was a population-based quasi-experimental study to evaluate the effect of an integrated intervention package. The design of the intervention was built upon the formative research study conducted previously under the early implementation phase of the "Strengthening Evidence for Programming on Unintended Pregnancy" (STEP UP) research program consortium (RPC).

\section{STUDY AREA}

This study was done in four purposively selected urban slums of north and south parts of Dhaka city corporation, Bangladesh, based on the formative research study findings [5]. Two of the slums (Mirpur and Kamrangirchar) were randomly assigned to the intervention group and another two (Shekhertek and Rayerbazar) to the comparison group. The assignment of the slums between the groups was independently done by a statistician based on a computer generated random sequence. The selected slums had definite geo-political boundaries and were at a distance from each other. Overlapping of populations among the slums was therefore not expected. It was further anticipated that the random assignment of the slums between the groups ensured that the study populations were essentially equivalent during the formative study.

\section{STUDY DURATION}

The study period was between July 2014 and August 2016. The study was completed in different phases as described below:

1. Preparatory and design phase: July 2014 to February 2015

Major activities under this phase were as follows:

- Meeting with District Registrar, Dhaka, for getting his approval to include Marriage Registrars from the intervention areas in the current study.

- Meeting with key personnel of Health Nutrition and Population Program (HNPP), and brac Education Program (BEP) of the international NGO brac in relation to the formation of married adolescent girls' club;

- Meeting with brac HNPP Program Managers to include them in the study and to find out ways to deploy brac Shasthya Shebikas (SS) as part of the study.

- Meeting with brac SSs and including their line supervisors in the current study.

- Meeting with and training of marriage registrars in the intervention areas.

- Development of behaviour change communication (BCC) materials for the married adolescent girls. 
2. Implementation of Intervention: March 2015 to February 2016

Major activities under this phase were as follows:

- Logistic supplies and technical support to the different components of the research implementation team.

- Formation and running of the married adolescent girls' club sessions through club leaders.

- Regular follow up of the activities of brac Shasthya Shebikas and documentation of their daily performance.

- Implementations of the marriage registrars' activities and documentation of their work.

3. Process Documentation: March 2015 to February 2016.

Major activities under this phase were as follows:

- Monitoring and supervision of data collection on different intervention components.

- Conduction of key informant interviews (KIIs) with the marriage registrars, brac Shasthya Shebikas, club respondents and club leaders to track the progress and provided feedback.

4. Evaluation of Intervention: March 2016 to June 2016

Major activities under this phase were as follows:

- Quantitative survey with married adolescent girls aged $14-19$ years

- Qualitative data collection among married adolescent girls' clubs members, and their husbands.

\section{DATA COLLECTION}

Both quantitative and qualitative techniques were applied as appropriate to document and evaluate this intervention.

In the quantitative component, the interviewers started by spinning a bottle at the central location to determine the first household based on the direction of the bottle. All households in the direction determined by spinning the bottle were visited and each eligible married adolescent girl in the selected household was invited to participate in the study. If a selected household had two or more eligible married adolescent girls, one was randomly selected by lottery method. If an eligible married adolescent girl lived in a selected household but was absent at the time of the visit, the interviewer obtained information on her availability from household members or their neighbours and scheduled a re-visit. The process of identifying married adolescent girls was repeated until the required sample size was obtained. 
A structured questionnaire was developed in English for the quantitative survey and later was translated into Bengali for data collection. Information on married adolescent girls' socio-economic including demographic characteristics; childbearing experiences and intentions; knowledge, attitudes, access to and practices regarding family planning methods and issues; as well as awareness of, attitudes towards, and experiences with the interventions were captured. Informed written consent was obtained from study respondents prior to interviews.

For the qualitative part, semi-structured interview guidelines were used for different types of respondents. Based on the objectives, different checklists and guidelines for in-depth interviews (IDIs), key informant interviews (KIIs) and focus group discussions (FGDs) were drafted. The key issues addressed in the checklists were to explore, how he or she experienced and benefitted after being exposed to the interventions; what were the major challenges implementing the interventions and how these interventions can be sustainable.

\section{BRIEF DESCRIPTION OF THE INTERVENTION COMPONENTS}

The interventions were implemented in the two slums over a period of 12 months and included the following activities: 1) Formation of married adolescent girls' club 2) Strengthening brac Community Health Volunteers (Shyastha Shebika) activities on family planning counselling with emphasis on long acting reversible contraceptive methods, and 3) Involving Government Marriage Registrars (Kazis) in family planning services promotion.

\section{Intervention component 1: Formation of married adolescent girls' club}

The Government and several NGOs in Bangladesh run a number of adolescent clubs both in rural and urban areas of the country mainly targeting unmarried adolescent boys and girls. The international NGO, brac, has extensive experience in running adolescent clubs. As part of this component, collaboration was done with brac to replicate their model for married adolescent girls clubs in urban slums. brac club venues were used to run the married adolescent girls' clubs.

Each club had a club leader; ten club leaders were recruited and trained to run the married adolescent girls' clubs. The club leaders were trained on - i) early marriage and its consequences; ii) unintended Pregnancies (UP) and its health and social consequences; iii) importance of contraceptive method use in reducing unintended pregnancy and improving maternal and child health; iv) information about available FP methods and the FP service centres; v) role of marriage registrars in FP information provision; and vi) Male contribution in FP. 
Eight out of the ten club leaders were recruited from existing brac adolescent clubs, and two were working as teachers in brac schools. Quarterly refresher training was conducted for the club leaders throughout the intervention period. A short training manual was provided to the club leaders as well. At the preparatory stage, icddr,b field research team members, brac Shyastha Shebikas, and club leaders did door to door visit and prepared a list of married adolescent girls which was updated regularly. To ensure full attendance of the married adolescent girls at the club sessions, the club leaders, and icddr,b field research team members used to visit all the households in the respective club areas to invite all listed married adolescent girls before conducting each club session.

The club activities took place in existing ten brac club venues in two intervention areas. A yearly calendar was prepared to run the clubs. Every week, one club session was conducted in each venue and thus four club sessions in a month. Therefore, in each month a total of 40 batches were formed. On an average, 20 married adolescent girls participated in each club session. By this way, around 800 $\left(40^{*} 20\right)$ married adolescent girls were covered in each month through the club sessions. Each married adolescent girl had the scope of attending 12 club sessions during the one year intervention period. Throughout the project period, around 1600 married adolescent girls participated in the club activities.

Duration of the club sessions was approximately between one and half to two hours and was adjusted based on time availability and interest of the married adolescent girls towards the club sessions. Club leaders used to maintain an attendance sheet for the club respondents. A curriculum for the club sessions was prepared by the research team that was followed throughout the year.

A pictorial family planning pocket-book bearing simplified messages on family planning issues was developed and printed in Bengali language using the existing BCC materials collected from Information, Education and Motivation (IEM) unit of Directorate General of Family Planning (DGFP). The pocket book had illustrations, enclosed with a key ring at it's end, handy to keep in the handbag of the married daolescent girls, and served as a multipurpose tool. To make it eye-catching to the young girls, a mirror was placed on its cover and the remaining part of the cover was decorated with colourful stones and attractive embroidery materials (Figure 1). This pocket book was distributed to all of the married adolescent girls who attended the club sessions. 


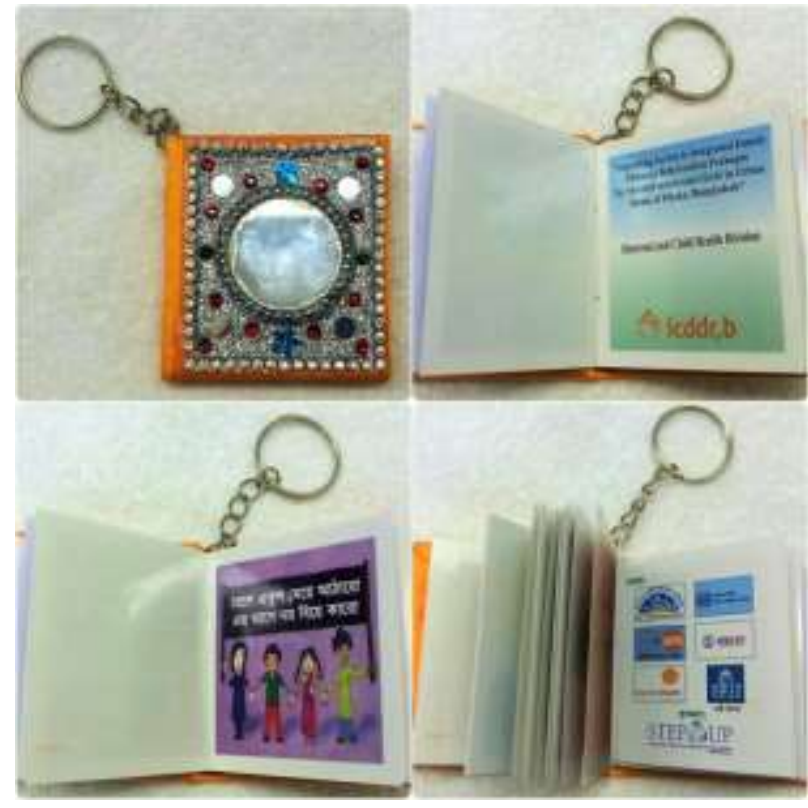

Posters, flipcharts, and banners on family planning information and messages were displayed inside the club rooms. Some recreational facilities such as carom board/ludo board (indoor games), educational story books (for those who can read) were also kept as part of the club activities. After ending the club sessions, interested club members could spend times by playing carom/ludo and/or reading story books.

In every three months, there was arrangement of assessment tests in which the club respondents took part and that created a lot of interest among them. In the assessment test, twenty questions were asked on the topics discussed in the club sessions. Based on the assessment results, they were awarded with token prizes for further motivation.

Besides regular discussion topics in the club sessions, there was arrangement of entertainment activities like dance, music, and drama in participation of the married adolescent girls. The drama scripts were based on real life stories of some of the club participants, were collected by the field implementation team members as case studies. In the last month of intervention (February 2016), the dramas were staged by the married adolescent girls in every club venues. From selected case studies, a story book named "Aalor Janala" or "Window of Hope" was published. 


\section{Intervention component 2: Involvement of brac community health volunteers (Shyastha Shebika)}

brac has community health volunteers, better known as Shasthya Shebika, are locally selected from their place of residence. They visit about 200 households in a month within their catchment areas and are trained in imparting health education, nutrition and family planning. They sell FP and health commodities, including oral rehydration saline, safe delivery kits, contraceptive pills, condoms and sanitary napkins at the community level and earn some income from this. They are further involved in early identification of pregnancy and provision of care to new born. They also motivate women and families to get the MNCH services.

A total of 67 Shyastha Shebikas from both the intervention areas were included in this study. The Shyastha Shebikas were trained to provide comprehensive information on correct and consistent use of short-acting methods and to promote the uptake of long acting reversible contraceptive (LARC) methods, emphasising on any misconceptions on the different available methods, including fear of side effects, and complications, and to make referrals for LARC among married adolescent girls who need to space pregnancies for longer periods.

The Shyastha Shebikas used a referral form provided by icddr,b to refer the married adolescent girls for receiving LARCs. This referral form had three parts - one part was kept in brac office, second part was given to the client, and the third part was for the referral centre. For validation purpose, the study personnel cross-matched all the three parts of the referral form (Figure 2).

The Shyastha Shebikas were also requested to accompany married adolescent girls to the referral facilities, who were interested to receive LARC. Furthermore, they visited the married adolescent girls clubs regularly which were recorded in a separate attendance book. brac usually organizes monthly meeting for Shyastha Shebikas at their branch offices. icddr,b field research team members regularly attended the monthly meetings to collect updated information and to provide necessary directives to the Shyastha Shebikas for smooth operation of the intervention activity. 
Figure 2: Referral form used by Shyastha Shebikas for promotion of LARC

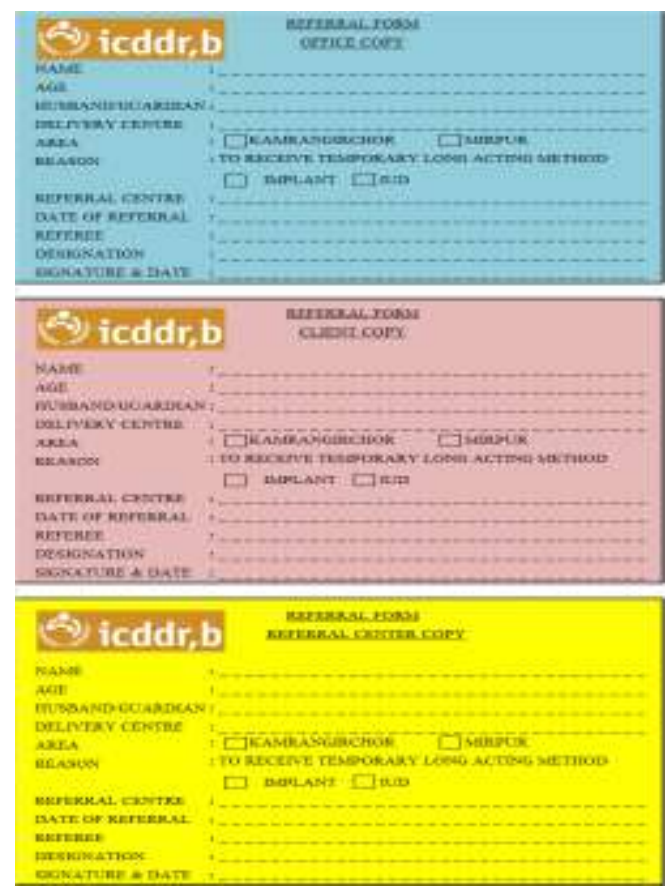

\section{Intervention component 3: Involvement of marriage registrars (Kazi)}

Muslim Marriage Registrars, named Kazis ${ }^{3}$ register Muslim marriages and divorces in their defined geographical locality. In Bangladesh, Hindu and Christian marriage registration is not mandatory as that of Muslims. The Marriage Registrars are under comparison of the Ministry of Law, Justice and Parliamentary Affairs. To implement this component, collaboration with the Ministry of Law, Justice and Parliamentary Affairs was developed to include Muslim, Hindu and Christian marriage registrars from two intervention areas.

A total of 16 marriage registrars and 26 marriage counsellors (assistant to marriage registrar) were included in this study. They were mostly familiar and had more than ten years of working experience in registering marriage in the community.

The marriage registrars were trained on the similar topics as that of the club leaders that included, i) early marriage and its consequences; ii) unintended Pregnancies (UP) and its health and social consequences; iii) importance of using family planning methods in reducing UP and improving maternal and child health; iv) information about available FP methods and the FP service centres; v) role of Marriage Registrars in FP information provision; vi) male contribution in FP etc. As a part of the intervention, after marriage registration, the marriage registrars were requested to counsel the couples

\footnotetext{
${ }^{3}$ Kazis are persons appointed by the Government of Bangladesh under the Muslim marriages and divorces registration Act of 1974 to register Muslim marriages and divorces within a given area or locality.
} 
from their respective religious point of views, and to distribute the FP pocket book key ring to the newly wed husband as a gift. The aim of introducing this FP pocket book immediately after the marriage registration was to reach the male members and to involve them in family planning related issues.

A register book was developed and distributed among the marriage registrars to keep the records of marriage registration and pocket book key ring distribution during the intervention period. icddr,b field research team members visited marriage registrars' office biweekly to oversee their activities and to collect required information.

A video documentary (docudrama) on all three components of the interventions has been developed both in Bengali and English, and are available in the following link: https://www.youtube.com/playlist?list=PLa-SLBHQdYJySKhez16UOvSOBSsJG0ydZ

\section{FIELD IMPLEMENTATION TEAM MEMBERS}

One field research manager (FRM), two field research supervisors (FRSs) and ten field research assistants (FRAs) were recruited for monitoring and supervision of the intervention activities. One FRA was assigned for each of the clubs; the FRAs closely worked with the club leaders for bringing the married adolescent girls to the club and assisted club leaders to conduct club sessions. The FRSs were appointed to supervise the works of FRAs and one FRS was in charge of one intervention area. The FRM was responsible for overall field implementation of the three intervention activities of the project and for quality assurance.

\section{PROCESS DOCUMENTATION}

An effective process documentation, monitoring and supervision system was established by deployment of the field implementation team. The team remained in the field throughout the study implementation period. Process monitoring of the interventions occurred during the period of implementing the interventions to provide an understanding of what was occurring within the program, how the program was developed, and how and why it was deviated from its initial plans and expectations, if any. Monitoring was a continuous process aimed at assessing progress in the implementation of the project and undertaking refinements of interventions when necessary. Process monitoring focused on the following questions:

- How were MAGs recruited into the MAG clubs?

- How many MAGs were able to attend the club sessions?

- What were the needs of the MAGs during the club sessions and how the club facilitators responded to them? 
- In what ways was marriage registrars/marriage counsellors engaging (successfully and unsuccessfully) with newly married adolescent girls and their husbands, and why?

- In what ways are brac Shyastha Shebikas providing comprehensive FP information, counselling and bringing the MAGs to the facility for long acting reversible contraceptive methods?

- How were MAGs and their partners linked to reproductive health and FP services?

- What worked well (or not) and why? What were the strengths and weaknesses of the program from the perspective of respondents and other actors (marriage registrars/marriage counsellors, club leaders, and Shyastha Shebikas)?

- What contextual factors, if any, affected the implementation of the interventions?

As part of process documentation, 32 qualitative interviews were conducted that included in-depth interviews (IDIs) with 20 married adolescent girls, four club leaders, four Shyastha Shebikas, and key Informant Interviews (KIls) with four marriage registrars. Apart from conducting the interviews, observation of four club sessions in two intervention areas were also done.

\section{In-depth interviews (IDIs) with married adolescent girls}

In-depth interviews with twenty married adolescent girls who attended the club sessions were conducted to gather their feedback regarding the club activities, their expectation from the club sessions, responses they received from the club leaders on their queries to the discussion topic, and about Shyastha Shebikas' activities. Married adolescent girls from the clubs were selected based on numbers of their club participation and were categorized into two groups: those who participated in 1 to 5 club sessions, and those who participated in 6 to 10 club sessions.

\section{In-depth interviews (IDIs) with married adolescent girls' club leaders}

In-depth interviews with four club leaders was done to explore their insights regarding strengths and weaknesses of the club activities, and also about brac Shyastha Shebikas' activities, involvement with the club activities.

\section{In-depth interviews (IDIs) with Shasthya Shebikas}

In-depth interviews with four Shasthya Shebikas were conducted to explore their activities on providing comprehensive FP information, counselling, and accompanying those married adolescent girls to the FP service centres who were interested to receive long acting reversible contraceptive (LARC) methods, and about their perception regarding the married adolescent girls club and club leaders. 


\section{Key informant interviews (KIls) with marriage registrars}

Key informant interviews with four of the marriage registrars were conducted to identify the ways they engaged (successfully and unsuccessfully) themselves with their assigned intervention activity, and to explore how their role impacted on disseminating knowledge on using contraceptive method as well as to prevent unwanted pregnancy among married adolescent girls.

The club leaders and Shyastha Shebikas for IDIs, and the marriage registrars for KIls were purposively selected based on their performance - high and low - following regular programme monitoring document of the icddr,b field implementation team.

\section{Club session observation}

Observation of four club sessions, two from each of the intervention area, was also done as part of process documentation. Objective of the club session observation was to watch married adolescent girls' participation in clubs as well as club leaders' capacities to facilitate the sessions, and respond to the queries from the married adolescent girls.

\section{EVALUATION OF INTERVENTION}

Evaluation of the intervention was done using a mixed-method approach of data collection that involved: i) Community based survey (quantitative); ii) In-depth interviews (IDIs) with married adolescent girls and their husbands (qualitative).

\section{Quantitative survey}

After completion of the one-year intervention, a community-based survey was conducted with 1601 married adolescent girls equally distributed between intervention and comparison areas. Firstly, sample size for the intervention sites was computed based on the desire to detect a 10 percentage decrease in the proportions of married adolescent girls reporting unintended pregnancy (from $53 \%$ to $43 \%$ based on the findings from the baseline survey) [5]. Considering an absolute precision of 0.05 with $95 \%$ confidence interval and $80 \%$ power, sample size was calculated. Sample size was inflated by $20 \%$ to account for non-response rate and refusals and the fact that $22 \%$ of the married adolescent girls will not be pregnant at the time of the survey (based on the findings from the baseline survey) [5].

\section{Qualitative Interviews}

During the survey, a total of 43 in-depth interviews (IDIs) and two focus group discussions (FGDs) were conducted among the following groups: 


\section{In-depth interviews (IDIs) with married adolescent girls}

In-depth interviews with 22 married adolescent girls were done. Respondents for IDI were selected among the following groups: who attended the club sessions; who had some communication with the Shyastha Shebikas regarding LARC uptake; and who had received key rings from the marriage registrars after marriage registration. Respondents for IDIs were further categorized and were purposively selected following the criterion below:

i) Married adolescent girls with children (4);

ii) Married adolescent girls without children (4);

iii) Married adolescent girls with history of unintended pregnancy (4);

iv) Married adolescent girls who received LARC through Shyastha Shebikas (4);

v) Married adolescent girls who received LARC not through Shyastha Shebikas (4);

vi) Married adolescent girls who received FP pocket book with key ring from the marriage registrars (2).

The purpose of enrolling different categories of married adolescent girls was to gather variations on family planning perspectives and to identify the changes among the married adolescent girls in FP related knowledge through attending the club sessions, Shyastha Shebikas' visit to their home, and counselling and information dissemination by the marriage registrars. The IDIs also explored the married adolescent girls' perspectives related to the club activities, their needs from clubs, Shyastha Shebikas, and from marriage registrars. Moreover, understanding of the married adolescent girls' perception and insights in improving the club sessions; club leaders', Shyastha Shebikas', and marriage registrars' activities was also important.

\section{In-depth interviews (IDIs) with husbands of married adolescent girls'}

A total of 17 husbands of the married adolescent girls (who participated in IDIs) were interviewed for further exploration about spousal communication and discussion among spouses related to FP. Despite repeated attempts, conducting IDIs with five of the husbands (out of 22) could not be done as they went out of the study areas and was out of contact. They were: husband of married adolescent girl without children (1); husbands' of married adolescent girls who received LARC not through Shyastha Shebikas (2); and husbands' of married adolescent girls who received key rings from the marriage registrars (2). 
In-depth interviews (IDIs) with Shyastha Shebikas

In-depth interviews with four (4) purposively selected Shyastha Shebikas who assisted the married adolescent girls to receive LARC during project period were conducted. These interviews explored the Shyastha Shebikas experiences in providing information to the married adolescent girls on LARC, counselling them in receiving the method, and any barriers faced in conducting their job.

Focus group discussions (FGDs) with non-users of married adolescent girls' clubs To identify challenges related to club participation, two (2) FGDs were conducted in the two intervention areas with non-users of married adolescent girls' clubs, who never had opportunities to participate any of the club sessions despite listed and invited repeatedly by the club leaders and field implementation team members. They were considered as non-users because after several invitations, they could not attend even a single club session.

\section{INCLUSION AND EXCLUSION CRITERIA}

All the respondents enrolled in the survey and participated in qualitative interviews were between 14-19 years of age, had lived in the slum for more than a month, and married for more than three months. The married adolescent girls who were divorced or separated, had experience on participating any such intervention program or education training on family planning issues, physically handicapped, below 18 years of age and whose spouse or in-laws did not grant consent, as well as those who had not grant individual assent or consent was excluded from the study.

\section{DATA ANALYSIS}

\section{Quantitative data analysis}

Interviews with the married adolescent girls' during the community based survey helped in determining the effectiveness of the interventions. The data were entered into a computer database using Oracle 11G.R2 (Oracle Corporation, California, USA) and exported to STATA 13.1 (Stata, College Station, TX, USA) for analysis. Simple frequency tables, cross-tables with chi-square test to examine the association between two variables between married adolescent girls in the intervention and comparison areas were used. The interventions were considered to be effective if significant change in the key outcome indicators were observed in the intervention than in the comparison areas. P-value less than 0.05 were considered as statistically significant; some of the $p$-values could not be calculated because of small sub-group numbers. 


\section{Qualitative data analysis}

All the study respondents were recruited purposively following sampling criteria. Separate semistructured data collection tools were used to collect data for different group of samples. Data analysis of the study was performed thematically. Two field research assistants from Anthropology background were responsible for data collection, preparing transcriptions and assisting in the data analysis. Several steps were followed during data analysis:

- All recorded interviews were transcribed verbatim and then reviewed by research team members.

- Researchers read transcribed interviews thoroughly in order to gain familiarity with the data and identified key issues, common ideas and recurrent concepts.

- Transcribed interviews were systematically coded, indexed and synthesized for enabling interpretation of the findings. Study researchers were involved to assess the reliability of the data.

- Subsequently, key themes and sub-themes were identified by drawing attention to priority issues based on the study objectives.

- Findings on the same issues discussed by various respondents that were compared by preparing two by two matrix to strengthen the validity of the findings and to assess their similarities and differences.

- Emerging themes and sub-themes were then analyzed to understand the acceptability and feasibility of the three components.

- Word for word quotes were used to indicate respondents' particular point of views regarding their experiences.

\section{ETHICAL CONSIDERATIONS}

The study received ethical approval from the Ethical Review Committee (ERC) of icddr,b and the Institutional Review Board (IRB) of Population Council, US. Written informed consent was obtained from each participating respondent. The consent process involved clearly explaining the purpose of the study, the type of information to be collected, the risks and benefits of participating in the study, the mechanisms for maintaining confidentiality of the information, their rights of voluntary participation and withdrawal, and sources of additional study-related information.

According to the law of Bangladesh, the age of consent for participating in any research is 18 years. A group of the married adolescent girls (14-17 years) participated in this study were therefore classified as minors. For those respondents, informed consent was sought at two levels - spouses/parents-inlaw/guardians first, followed by the individual adolescent girl. Married adolescent girls indicated their 
willingness to participate in the study by assenting, only after their parents-in-law/guardians had given permission. Adolescents aged 18-19 years provided individual consent only.

The consent forms were read out aloud by interviewers whereupon the respondents were asked if they agreed to participate in the study. Special care was taken to obtain voluntary and fully informed consent in all cases. Participation in the study was completely voluntary; respondents were not provided with any inducements or incentives for participating in the study. 


\section{RESULTS}

In this study, qualitative interviews have been conducted in two phases: a) during process

documentation; and b) during evaluation of intervention (end-line survey). Qualitative findings from both phases have been compiled and have presented here collectively with the findings from the community based survey (quantitative).

\section{Socio-demographic characteristics of community based survey respondents}

In both intervention and comparison areas, on an average, majority (73\%) of the married adolescent girls were aged above 18 years, $22 \%$ of them were between $15-17$ years, and around $5 \%$ of them were less than 14 years old (Table 1). Nearly half of the respondents had completed primary level of schooling, $30 \%$ had completed $6-8$ years of schooling, while more than one-tenth had no formal education (Table 1).

One-third of the married adolescent girls in the intervention areas were working for earning money which was comparatively less among their counterparts in the comparison areas (14.8\%). Among those who worked for money, around one-fourth of them were garment workers in both the areas. Half of the married adolescent girls in the intervention areas were involved in handicrafts while in comparison areas it was $10.9 \%$. Serving as maid servants found lower in the intervention areas (10.5\%) than that of in the comparison areas (41.2\%). Nearly one-fifth of the married adolescent girls in both the areas were involved in other services such as tailoring, business, government/private job, etc (Table 1).

More than $90.0 \%$ of the married adolescent girls of both the areas got married before the age of 18 years; more than half of them did so by their parents' decision and majority of them $(>90.0 \%)$ had consent for their marriages (Table 1).

Table 1: Percent distribution of respondents' socio-demographic characteristics by intervention and comparison areas

\begin{tabular}{|c|c|c|c|}
\hline \multirow[b]{2}{*}{ Characteristics } & \multicolumn{2}{|c|}{$\%$ of the married adolescent girls } & \multirow[b]{2}{*}{$p$-value } \\
\hline & Intervention $(\mathrm{n}=799)$ & $\begin{array}{c}\text { Comparison } \\
(n=802)\end{array}$ & \\
\hline \multicolumn{4}{|c|}{ Age of respondents (in years) } \\
\hline$\leq 14$ & 3.4 & 5.6 & \\
\hline $15-17$ & 23.4 & 21.0 & \\
\hline$\geq 18$ & 73.2 & 73.4 & 0.063 \\
\hline \multicolumn{4}{|c|}{ Age of respondents' husbands (in years) } \\
\hline $15-20$ & 7.5 & 13.1 & \\
\hline $21-25$ & 50.4 & 51.4 & \\
\hline $26-30$ & 38.1 & 30.1 & \\
\hline
\end{tabular}




\begin{tabular}{|c|c|c|c|}
\hline \multirow[b]{2}{*}{ Characteristics } & \multicolumn{2}{|c|}{$\%$ of the married adolescent girls } & \multirow[b]{2}{*}{ p-value } \\
\hline & Intervention $(n=799)$ & $\begin{array}{c}\text { Comparison } \\
(\mathrm{n}=802)\end{array}$ & \\
\hline $31-45$ & 4.0 & 5.5 & 0.000 \\
\hline \multicolumn{4}{|c|}{ Education of respondents (in completed years) } \\
\hline No education & 13.9 & 10.8 & \\
\hline $1-5$ & 40.4 & 41.2 & \\
\hline $6-8$ & 31.9 & 28.9 & \\
\hline $9+$ & 13.8 & 19.2 & 0.009 \\
\hline \multicolumn{4}{|c|}{ Age at marriage of respondents (in years) } \\
\hline$\leq 14$ & 47.9 & 34.5 & \\
\hline $15-17$ & 48.9 & 55.5 & \\
\hline$\geq 18$ & 3.1 & 10.0 & 0.000 \\
\hline \multicolumn{4}{|l|}{ Husband stays with respondent } \\
\hline *Stays regularly & 91.2 & 93.9 & \\
\hline${ }^{* \star}$ Stays irregularly & 8.8 & 6.1 & 0.043 \\
\hline \multicolumn{4}{|l|}{ Type of marriage of respondents } \\
\hline Marriage by own choice & 48.4 & 41.0 & \\
\hline Marriage by parents' choice & 51.6 & 59.0 & 0.003 \\
\hline Consented to arranged marriage & $\mathrm{n}=412$ & $n=473$ & \\
\hline Yes & 91.8 & 94.1 & \\
\hline No & 8.2 & 5.9 & 0.175 \\
\hline Occupation status of respondents & $n=799$ & $n=802$ & \\
\hline Yes & 32.3 & 14.8 & \\
\hline No & 67.7 & 85.2 & 0.000 \\
\hline Types of occupation of respondents & $n=258$ & $n=119$ & \\
\hline Maid & 10.5 & 41.2 & \\
\hline Garment/factory worker & 20.5 & 25.2 & \\
\hline Handicrafts & 51.9 & 10.9 & \\
\hline Other services & 17.1 & 22.7 & 0.000 \\
\hline
\end{tabular}

*Husband stays with the respondent regularly

**Husband does not stay with the respondent and visits her once a week/month or bimonthly

\section{Respondents' qualitative interviews in two phases}

Respondents participated in the qualitative interviews conducted during process documentation and during evaluation of intervention has shown in Table 2 below:

Table 2: Respondents' participated in qualitative interviews in two phases

\begin{tabular}{|l|c|c|}
\hline Category of respondents & $\begin{array}{c}\text { During Process } \\
\text { Documentation ( } n=32)\end{array}$ & $\begin{array}{c}\text { During Evaluation of } \\
\text { Intervention }(n=43)\end{array}$ \\
\hline Married adolescent girls (MAGs) ( $n=42)$ & 10 & - \\
\hline Attended 1-5 club sessions & 10 & - \\
\hline Attended 6-10 club sessions & - & 4 \\
\hline Recently married with children & - & 4 \\
\hline Recently married without children & - & 4 \\
\hline Having unintended pregnancy & - & 4 \\
\hline Received LARC through SSs & - & 4 \\
\hline Received LARC not through SSs & - & 2 \\
\hline Received FP pocket book from marriage registrars & & \\
\hline
\end{tabular}




\begin{tabular}{|c|c|c|}
\hline \multicolumn{3}{|l|}{ Husbands' of married adolescent girls $(n=17)$} \\
\hline Recently married with children & - & 4 \\
\hline Recently married without children & - & 3 \\
\hline Category of respondents & $\begin{array}{c}\text { During Process } \\
\text { Documentation }(n=32)\end{array}$ & $\begin{array}{l}\text { During Evaluation of } \\
\text { Intervention }(n=43)\end{array}$ \\
\hline Having unintended pregnancy & - & 4 \\
\hline Received LARC through SSs & - & 4 \\
\hline Received LARC not through SSs & - & 2 \\
\hline Received FP pocket book from marriage registrars & - & 0 \\
\hline \multicolumn{3}{|l|}{ Club leaders $(n=4)$} \\
\hline Facilitated club sessions & 4 & - \\
\hline \multicolumn{3}{|l|}{ Shyastha Shebikas (SS) $(n=8)$} \\
\hline Providing comprehensive FP information & 4 & - \\
\hline Motivated MAGs to take LARC & - & 4 \\
\hline \multicolumn{3}{|l|}{ Marriage Registrars $(n=4)$} \\
\hline Counselling \& FP pocket book distribution & 4 & - \\
\hline Total & 32 & 43 \\
\hline \multicolumn{3}{|l|}{ Focus group discussion (FGDs) $(n=2)$} \\
\hline With non-users of MAGs' clubs & - & 2 \\
\hline \multicolumn{3}{|l|}{ Observation of club sessions $(n=4)$} \\
\hline By research team member & 4 & - \\
\hline
\end{tabular}

\section{Socio-demographic characteristics of the qualitative interview respondents}

Married adolescent girls: Out of the 42 married adolescent girls participated in the qualitative interviews, 25 of them were aged 18 years and above and almost all of them were Muslims (41 out of 42). Majority (25 out of 42) of them had 5-10 years of education, while only 3 had completed 10 or more years of schooling. Among the 42, nine were involved with income generating activities (Table 3).

Husbands of married adolescent girls: Among the 17 husbands of the married adolescent girls' interviewed, 12 of them were aged between 20 to 29 years, while few of them ( 3 out of 17) were above 30 years. Around half ( 8 out of 17) of the husbands' had no formal education; one of them had completed 10 or more years of schooling. Occupations of the husbands were different from each other, such as, industrial labourers (3), service holders (2), day labourers (5), garments workers (3), businessman (3) and driver (1) (Table 3).

brac Shyastha Shebikas: six out of eight of the brac Shyastha Shebikas interviewed were aged 30 years and above, and 6 of the SSs had no formal education (Table 3).

Club leaders: Half ( 2 out of 4 ) of the club leaders were aged 18 years and above and most ( 3 out of 4 ) of them had completed 10 or more years of schooling (Table 3). 
Marriage registrars: two out of four of the marriage registrars interviewed was aged below 40 years and all of them had completed at least 10 years of schooling. (Table 3 ).

Table 3: Socio-demographic characteristics of the qualitative interview respondents

\begin{tabular}{|c|c|c|c|c|c|}
\hline Age & $\mathbf{N}$ & Education & $\mathrm{N}$ & Occupation & $\mathbf{N}$ \\
\hline \multicolumn{6}{|c|}{ Married adolescent girls' $(n=42)$} \\
\hline Below 18 years & 17 & No formal education & 4 & Housewife & 33 \\
\hline \multirow{3}{*}{$18+$ years } & 25 & 1-4 years of schooling & 10 & Day labour & 7 \\
\hline & & $5-9$ years of schooling & 25 & Garments worker & 2 \\
\hline & & $\geq 10$ years of schooling & 3 & & \\
\hline \multicolumn{6}{|c|}{ Husbands' of married adolescent girls' $(n=17)$} \\
\hline Below 20 years & 2 & No formal education & 8 & Industrial labour & 3 \\
\hline 20 to 29 years & 12 & $1-4$ years of schooling & 3 & Service & 2 \\
\hline \multirow[t]{4}{*}{ Above 30 years } & 3 & $5-9$ years of schooling & 5 & Day labour & 5 \\
\hline & & $\geq 10$ years of schooling & 1 & Garments & 3 \\
\hline & & & & Driver & 1 \\
\hline & & & & Businessman & 3 \\
\hline \multicolumn{6}{|c|}{ Club leaders $(n=4)$} \\
\hline Below 18 years & 2 & Below 10 years of schooling & 1 & & \\
\hline $18+$ years & 2 & Above 10 years of schooling & 3 & & \\
\hline \multicolumn{6}{|c|}{ brac Shyastha Shebikas $(n=8)$} \\
\hline Below 30 years & 2 & No formal education & 6 & & \\
\hline $30+$ years & 6 & $1-5$ years of schooling & 2 & & \\
\hline \multicolumn{6}{|c|}{ Marriage Registrars $(n=4)$} \\
\hline Below 40 years & 2 & Above 10 years of schooling & 4 & & \\
\hline $40+$ years & 2 & & & & \\
\hline
\end{tabular}

\section{Married adolescent girls' club}

Out of total 12 club sessions conducted during the one-year intervention period, seven or more were attended by $48.3 \%$ of the married adolescent girls. Among the different components of the club sessions, learning session on various topics including use of FP methods, birth planning and spacing, consequences of unintended pregnancy, and early marriage was reported by the married adolescent girls' as the most attractive component (97.6\%) followed by knowledge evaluation and awarding system (73.3\%). Regarding the timing of club session conduction, majority of them (91.5\%) preferred the afternoon time. One-fifth of the respondents faced hurdles to attend the club sessions; major causes included household workload (53.4\%), and difficulty in time management because of outside job (26.7\%). Majority of the respondents (87.9\%) discussed the lessons learned among themselves and with others as well. Husbands (64.4\%) and neighbours (66.8\%) of the married adolescent girls were mostly their discussion partners regarding the topics learned from club sessions (Table 4). 
Table 4: Club attendance of respondents' and their feedback on club activities

\begin{tabular}{|c|c|}
\hline Characteristics & $\%$ of the respondents $(n=799)$ \\
\hline \multicolumn{2}{|l|}{ Club sessions attended } \\
\hline$\leq 3$ & 18.2 \\
\hline $4-6$ & 33.5 \\
\hline$\geq 7$ & 48.3 \\
\hline \multicolumn{2}{|l|}{ Club activities did like most } \\
\hline Learning session & 97.6 \\
\hline Evaluation test and awarding system & 73.3 \\
\hline Refreshment & 73.0 \\
\hline Drama & 66.3 \\
\hline FP pocket book with key ring & 43.6 \\
\hline Opportunity to meet/socialize with others & 23.9 \\
\hline Displayed BCC materials & 19.8 \\
\hline FP Booklet & 15.8 \\
\hline Playing indoor games (ludo, carom) & 8.0 \\
\hline Others & 0.3 \\
\hline \multicolumn{2}{|l|}{ Appropriateness of club session timing } \\
\hline Yes & 91.5 \\
\hline No & 8.5 \\
\hline \multicolumn{2}{|l|}{ Hurdles faced to attend club sessions } \\
\hline Yes & 22.0 \\
\hline No & 88.0 \\
\hline Type of hurdles & $n=176$ \\
\hline Household workload & 53.4 \\
\hline Could not manage time due to job & 26.7 \\
\hline Husband did not allow & 8.0 \\
\hline Father or mother in-laws did not allow & 6.8 \\
\hline Long distance from residence to club & 4.0 \\
\hline Others & 13.6 \\
\hline Discussed club session topics with others & $n=799$ \\
\hline Yes & 87.9 \\
\hline No & 12.1 \\
\hline With whom did discuss & $n=702$ \\
\hline Neighbor & 66.8 \\
\hline Husband & 64.4 \\
\hline Friends & 14.3 \\
\hline Relatives & 13.8 \\
\hline Sister & 11.7 \\
\hline Mother & 7.7 \\
\hline Sister in-law & 7.0 \\
\hline Mother in-laws & 5.4 \\
\hline Others & 2.0 \\
\hline
\end{tabular}

\section{Qualitative interview findings on married adolescent girls' club}

IDIs with the married adolescent girls explored that despite some difficulties to attend the club sessions regularly, all of them $(n=20)$ accepted the learning sessions very cordially. According to them, the strength of the club sessions was its learning aspects. They also reported that the interactive nature of 
the club sessions were very beneficial that helped them to dispose family planning method related misconceptions, fear, anxieties, and superstitions. The respondents also mentioned that the clubs created unique opportunity for them in exchanging their real life experiences with the peers which in turn helped them in changing their beliefs regarding family planning related behaviour and attitudes. One married adolescent girl with an unintended pregnancy told:

"It was a mistake to have a child at this stage. If I had the baby at a later stage and use any method that would have been better, I did not know anything before. No one suggested me to take any method or the worth of using a method. If I knew it before, I would have taken a method at the beginning. I have learned many things from the 'club apa (leader)' and 'icddr,b apa'. Not only that, many friends (peers) have developed here now; we can also share our problems and discuss the issues among ourselves. I am aware about many concerns now, this type of mistake will not be happening in my life again." (Age-14, Education- class 03, Occupation- Housewife).

The snacks provided by the project after the club sessions often brought joys to both the mothers and their children. At the time of conducting the in-depth interviews, almost all of the married adolescent girls requested the field implementation team members to continue the married adolescent girls' club sessions which manifest their warmth and attachment with the clubs. Attending in the clubs was also a space of ventilation for them. Furthermore, the married adolescent girls also mentioned about a knowledge chain which has been developed throughout the intervention period among the neighbouring peers. This indicates that the married adolescent girls who participated in the club sessions shared their take away home messages with other married adolescent girls who didn't attend the clubs. One married adolescent girl mentioned:

"I will teach other girls what I have learnt from the club sessions. I will say that bearing a child at early age may create problem, so use a contraceptive method. If she is convinced then she will not bear a child at her early age but if she is not convinced then she will continue with early child bearing (Age-17, Education- class 7, Occupation- Garments worker)"

Apart from usefulness, respondents also mentioned some user-related challenges to attend the club sessions. A few (2 out of 20 ) of the respondents mentioned that, it was difficult for them to attend the club sessions for an hour after conducting household work, like cooking, managing husbands, children, and family members. For some club respondents, session time was not suitable, because they used to take lunch after their husbands' return from work at late afternoon which overlapped with the club session time. In some of the places, the gas line for cooking was available with a better speed/flow only 
in the afternoon time, which hindered them to attend club sessions. Two out of 20 of the respondents felt that the sitting arrangement in the clubs (on the floor using a floor mat) could have been better than what was arranged. Some (4 out of 20 ) participants mentioned that there was no electricity connection in their club venues, which was difficult for them to stay there in summer time without fan.

\section{Peer network development}

Married adolescent girls had opportunities to discuss and exchange their knowledge acquired from the club sessions with their peers. Many married adolescent girls who could not attend the club sessions for several reasons, received first-hand family planning information from their peers who attended the club sessions. Club leaders also played a key role in this regard. Because the club leaders were local residents and familiar faces in the community, they used to invite and brought the married adolescent girls for club sessions. On the other hand, the BCC material - a small family planning pocket book attached with a key ring - was also a point of discussion among the married adolescent girls. They often gathered in a group and discussed the book contents. According to one of the respondents:

"...usually after lunch and during load shedding we all met at our rooftop. My sister read the pocketbook for all of us and we gathered knowledge from that... (Age-14, Education- no schooling, Occupation- Housewife)

\section{Involvement of brac shyastha shebikas}

Out of 67 Shyastha Shebikas' included and trained as part of the project, 42 had actively participated and performed their responsibilities assigned from the project.

More than one-third of the married adolescent girls in the intervention areas were visited by government and NGO health and family planning workers in different times in last 3 months prior to the interview period, which was found comparatively less $(26.8 \%)$ in the comparison areas. The Shyastha Shebikas' visits were more reported by the married adolescent girls in the intervention areas (74.0\%) than that of the comparison areas $(51.6 \%)$. About one-third $(72.8 \%)$ of the married adolescent girls were visited by the Shyastha Shebikas either regularly or irregularly which was significantly less $(37.4 \%)$ in the comparison areas. Significant variation in delivery of the family planning services by the Shyastha Shebikas was observed between the intervention and comparison areas. As regards to different services provided by the Shyastha Shebikas were more reported by the intervention group compared to the comparison group, that included: listing of pregnant women (73.6\% vs $40.4 \%)$, information provision on FP method use ( $54.2 \%$ vs $20.7 \%$ ), discussed on antenatal care services ( $45.1 \%$ vs $38.5 \%$ ), and selling FP commodities (35.2\% vs $7.9 \%$ ). Regarding IUD uptake during the intervention period, 
respondents from intervention areas $(79.1 \%)$ were comparatively more than that of the comparison areas $(71.4 \%)$ (Table 5).

Table 5: Respondents' feedback on Shyastha Shebika's visit by intervention and comparison areas

\begin{tabular}{|c|c|c|c|}
\hline \multirow[t]{3}{*}{ Characteristics } & \multicolumn{3}{|c|}{ Married adolescent girls (\%) } \\
\hline & Intervention & Comparison & p-value \\
\hline & $n=799$ & $n=802$ & \\
\hline \multicolumn{4}{|l|}{ Health/FP workers' visited in last 3 months } \\
\hline Yes & 37.0 & 26.8 & \multirow[t]{2}{*}{0.000} \\
\hline No & 63.0 & 73.2 & \\
\hline From where did they come? & $n=296$ & $n=215$ & \\
\hline NGO other than brac & 44.9 & 59.5 & 0.001 \\
\hline Government health workers & 1.4 & 2.8 & 0.246 \\
\hline brac health workers & 74.0 & 51.6 & 0.000 \\
\hline Others & 0.3 & 3.3 & 0.009 \\
\hline Shyastha Shebikas' did home visit & $n=799$ & $n=802$ & \\
\hline Regularly & 20.2 & 12.7 & \multirow[t]{3}{*}{0.000} \\
\hline Irregularly & 52.6 & 24.7 & \\
\hline Didn't visit & 23.4 & 52.9 & \\
\hline Don't know & 3.8 & 9.7 & \\
\hline \multicolumn{4}{|l|}{ Services usually provided by Shyastha Shebikas' } \\
\hline Listing of pregnant women & 73.6 & 40.4 & 0.000 \\
\hline Informed about FP methods & 54.2 & 20.7 & 0.000 \\
\hline Discussed about Antenatal care & 45.1 & 38.5 & 0.008 \\
\hline Sold FP commodities & 35.2 & 7.9 & 0.000 \\
\hline Helped women in getting services when referred & 4.5 & 4.1 & 0.700 \\
\hline Obtained LARC (IUD) during intervention period & $n=43$ & $\mathrm{n}=21$ & \\
\hline Yes & 79.1 & 71.4 & \\
\hline No & 20.9 & 28.6 & 0.498 \\
\hline \multicolumn{4}{|l|}{ Source of information for IUD } \\
\hline brac Shyastha Shebika & 52.9 & 13.3 & 0.009 \\
\hline icddr,b staff & 41.2 & & \\
\hline Married adolescent girls' club leader & 32.4 & & \\
\hline Kazi/ marriage registrar & 0.0 & & \\
\hline Other NGO workers & 23.5 & 26.7 & 0.814 \\
\hline Others & 14.7 & 60.0 & 0.001 \\
\hline
\end{tabular}

Proportion of referral of respondents' for long acting reversible contraceptive (LARC) method uptake by Shasthya Shebikas' found gradually increased with quarters during the intervention period (Figure 3). 
Figure 3: Pattern of long acting reversible contraceptive (LARC) method uptake among respondents

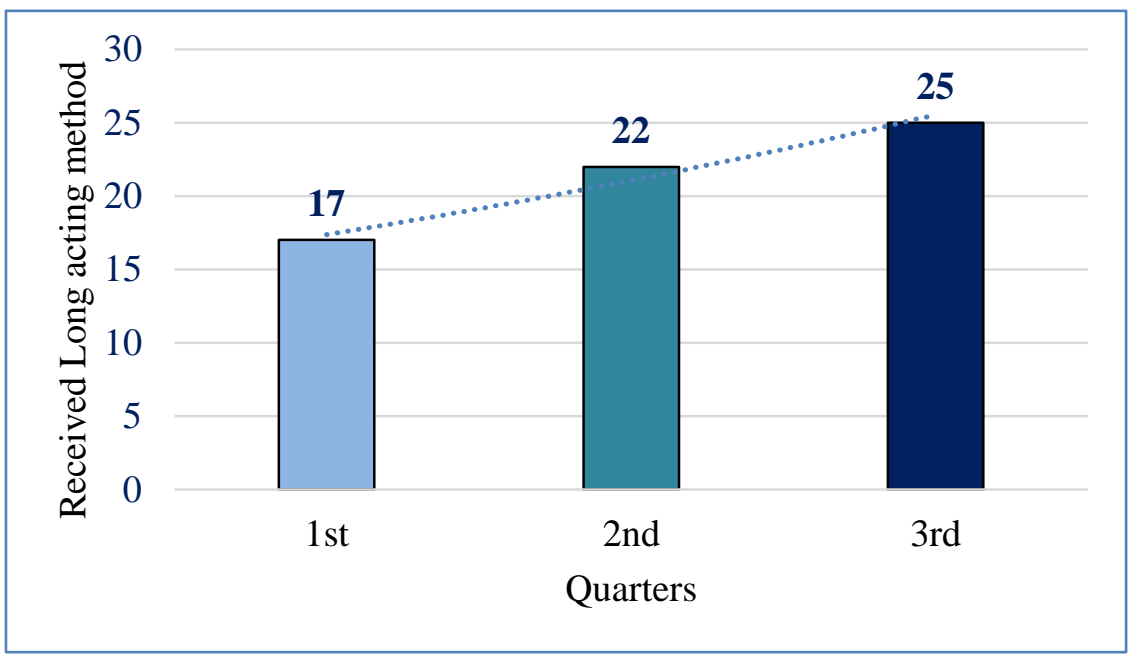

\section{Findings from qualitative interviews}

Although Shasthya Shebikas' (SSs) major responsibility was to counsel married adolescent girls to take long acting reversible contraceptive (LARC) methods, they also counselled them to be enrolled in the club sessions. Findings revealed that most of the married adolescent girls who received LARC, initiated communications with SSs by themselves. Majority of the married adolescent girls, who were contacted by SSs, received knowledge on unintended pregnancy prevention and early child bearing.

Findings from both process documentation and survey data revealed various benefits for married adolescent girls through the SSs involvement in the project. A new relationship was established between married adolescent girls and SSs. As the SS were much known in the community, many of the married adolescent girls had previous communication with them - mostly related to pregnancy and delivery. Among all the married adolescent girls interviewed ( $n=42)$, eight reported about their previous communication with the SSs and 28 of them had developed new relationship during the project period which further helped them in direct communication with the SSs regarding contraceptive method use. One married adolescent girl expressed her concern:

"I received tremendous benefits from Shasthya Shebika Khala (aunt); if she was not there, I would have not managed to receive the long acting reversible contraceptive method (LARC)

\section{(Age-20, Education-class 5, Occupation- Housewife)}

Another married adolescent girl who received long acting reversible contraceptives confides with a Shasthya Shebika: 
'(This knowledge) from 'Khala (SS)' was useful for me; I have a baby and I have received a long acting method after getting all the information about it from 'Khala'. Now I am confident about this and I hope and believe that I will be able to motivate others, who are in a similar situation like me" (Age-18, Education- class 8, Occupation- Housewife)

Shasthya Shebikas were well accepted among the married adolescent girls because of their continuous and long-time engagement with the community; easy access to the community even to all the family members (husbands and in laws). The referral for LARC from the SSs helped the married adolescent girls in identifying the FP service centres and in receiving the methods properly. However, one Shyastha Shebika shared her experience about convincing the married adolescent girls' and their family members for LARC through the following quote:

"Implants (a long acting reversible contraceptive) require a small operation while to insert or even to remove. The married adolescent girls often show their concerns about unforeseen side effects related to this. Sometimes their mothers', aunts', or in-laws prohibit them not to insert those because of the belief that when someone will die, they have to remove it before funeral and one should not be buried with a foreign particle inside her body. The community people also believed that they will be accountable to god for doing this kind of activity (inserting implant within the body) in their life. The community people talked too much and showed their concerns regarding those issues but we usually tried to convince and manage them." (Age-

\section{5, Education- class-02, Study area-Kamrangirchar)}

\section{Marriage registrars' role in delivering family planning messages}

A total of 16 Marriage Registrars, 13 from Muslim (Kazis), 2 from Hindu, and one from Christian religion were involved with the project activity, but except the Muslim marriage registrars (Kazis) no family planning message dissemination or distribution of FP pocket book was observed among the marriage registrars from other two religions.

All the Kazis were found well aware about the project's objectives and the importance of getting knowledge about the consequences of unwanted pregnancy, keeping family small and use of contraceptive methods.

During the entire intervention period, the Kazis delivered the FP pocket book to 52 newlywed couples who were identified from the registry books supplied from the project for record keeping. Among them, 26 of the married adolescent girls were from the intervention areas, 15 were from other parts of Dhaka city, and 11 were from outside Dhaka city. The Kazis had the opportunity of providing the pocket book 
to the husbands of 44 married adolescent girls. They could not distribute the FP pocket book to the remaining eight couples because of the unapproachable situation during marriage conduction.

The Kazis used to deliver the FP pocket books after completing the marriage registration at their offices and/or at homes of the bridegroom where the marriage ceremony took place. KII with the Kazis explored that majority of the slum dwellers usually came to their offices for marriage registration rather arranging it at their homes or some other places like community centres. Kazis also mentioned that they could deliver the FP pocket book to the newlywed couples more at their offices than at the brides' homes or other places. Because they often felt it difficult and embarrassing discussing family planning issues and distributing the FP pocket book in front of many people when the marriage ceremony took place at home or other places. One of the Kazis' mentioned:

"During marriage ceremony, it was very difficult to discuss the family planning related topics with the newlywed couples in front of parents, other family members, relatives, and guests. This is embarrassing to suggest like 'do not bear a child immediately when you are still an adolescent'. Is not it a shame?" (Age- 40, Education- PhD, Study area- Mirpur)

Delivering the FP pocket book to the couples also attracted other guests to that and created increased demand of the FP pocket book among those who were not part of this intervention and ultimately caused chaos sometimes. After experiencing that, the Kazis suggested the couples to visit their offices at a convenient time to receive the FP pocket book. Some of the couples came to the Kazi offices along with their relatives or guardians (father, mother, in-laws, and/or other relatives) that did also hamper Kazis' activities in delivering complete messages of the FP pocket book due to lack of privacy. In those cases, they delivered the pocket book only saying that the book can help the couples in building up their family better. Kazis also mentioned that they only felt free and could elaborately describe all the information related to family planning if the bride and the groom (the newlywed couples) came to their offices without any family members or relatives accompanying them

As a project requirement, the Kazis usually had distributed the FP pocket book among those couples where the bride was under 19 years of age. The Kazis felt that messages provided in the FP pocket book could be highly beneficial for the newlywed couples. They also mentioned that the couples who received the FP pocket book expressed their appreciation and positive feedback about that. But the Kazis' had also pointed out that illiteracy of majority of the adolescent girls was a barrier for going through the pocket book exclusively. The following excerpts highlighted Kazis perception about the low literacy of the MAGs: 
“.... The adolescent girls' are mostly illiterate and that's why they are unaware. They may keep the pocketbook aside; even they may hang it somewhere or use it as a key ring only. Most of them did not go to school neither they had any kind of education. So, providing only a pocket book is not adequate to educate them on family planning issues." (Age- 60, EducationSSC, Study area-Mirpur)

Kazis also mentioned that they had particularly suggested the uneducated couples to get help from their nearest educated friends in reading the contents of the FP pocket book and in understanding its messages.

The FP pocket book was supplied with a box, the design of which resembled like a condom packet. This sometimes put the newlywed couples and the Kazis in an embarrassing situation and they felt ashamed assuming that the Kazis were giving them a packet of condoms. After this observation, the Kazis were suggested to take out the FP pocket book from the box and keep it open during delivering to the newlywed couples. One of the Kazis mentioned:

"While I provided the FP pocket book to a couple for the first time, I was very embarrassed. Because of the size of the box...they thought that I was giving a condom packet, birth control pill, or something like that... they did not utter anything about it, but I guessed that from their body language. Initially, they did not want to receive the packet but while I opened it up and showed them the FP pocket book, they were convinced." (Age- 35, Education- HSC, Study area-Kamrangirchor)

The study team tried to follow up the couples identified from the Kazis' registry book to explore their feedback and impact after receiving the FP pocket book from the Kazis. However, difficulties arose to follow-up the couples during the end line survey. Sometimes the newlywed couples or their guardians were reluctant to provide necessary information like- age, contact number, present and permanent addresses of the couples for record keeping.

Among the 52 couples, contact numbers of only 34 were available in the registry book of the Kazis; of which, mobile phone of the 18 couples found switched off, and after maximum try for three times, 16 of the couples were finally communicated. Four of them were agreed for participating in the IDIs, but as a final point, only two of the married adolescent girls provided informed consent and participated in the indepth interviews; however, their husbands' were out of reach. Internal (within slums of Dhaka city) and external (Dhaka to native village) migration also caused difficulties in tracking the newlywed couples. 
At the time of interview, both the respondents were pregnant: one of them had seven months and the other one had six months pregnancy. Both wanted to delay their pregnancies. But one of the respondent's husbands insisted her to take the first baby soon and then giving space before the next child. Her husband had the perception that using oral pill from the beginning may cause infertility. He argued with his wife about that issue and referred an example of his sister-in-law who used to take oral pills after her marriage and had faced trouble when desired for a child, and finally failed to have one. The other respondent described her pregnancy as mistimed because she had the desire of taking a child after some days but forgot to take pill on regular basis. Both the respondents mentioned that they have learned about spacing between two pregnancies from the FP pocket book that they wanted to follow during their next pregnancies.

One of the respondents mentioned that she had attended some of the club sessions and had also received the FP pocket book and related information from the Kazi but the other respondent had no exposure to the married adolescent girls' clubs. According to both of them, Kazis could not spend much time on explaining the FP pocket book rather than just delivering that. The respondent, who had experience of exposure to both clubs and the Kazi, gained better knowledge on all aspects of unintended pregnancy and family planning issues than her peer. To give a proper space between two pregnancies, both of them were found determined to use long acting reversible contraceptives (LARC) after their child birth. They had also convinced their husbands on birth spacing and using of LARC as a perfect method during the spacing.

Often it was difficult to read and understand the FP pocketbook for couples who had not enough education; so they did not put much attention to that. Similar concern from the Kazis was reflected in one of the respondent's statement:

"I had tried to read the book but it was difficult for me and my husband to understand all the issues properly...... if there were someone to explain the book explicitly it would have been better for us." (Age-18, Education-class 06, Occupation-housewife)"

One of the respondents mentioned that she and her husband had read the FP pocket book together, tried to understand that to the best of their ability and knowledge, and had discussed about their plan for a happy family and birth spacing before having another child. Husband of the other respondent had read the FP pocket book but did not share or discuss any information with his wife directly; she had gained more relevant information from her neighbours and friends who also had received the FP pocket book from the married adolescent girls' clubs. She had also attended three club sessions and had 
observed the dramas organized by the club members. She also gave advice to her relatives and peers to use contraceptive methods.

\section{Knowledge and perception of married adolescent girls about early marriage, early pregnancy, birth spacing, and FP method use}

Married adolescent girls' knowledge and perception about age at first marriage, age at first pregnancy, spacing between two births, and family planning method use by intervention and comparison areas is summarized in Table 6. Almost all of the married adolescent girls felt that the ideal age at first marriage and first birth should be 18 or more than 18 years. However, no significant variation was found in the perceptions of married adolescent girls between the intervention and comparison areas. Around threefourths of the married adolescent girls from both the intervention and comparison areas perceived that the ideal birth spacing should be more than 5 years followed by $3-5$ years ( 25.7 vs. 20.6 ), and $\leq 2$ years (2.0 vs. 4.8) respectively; significant differences in perception between the intervention and comparison areas also observed. Almost all of the married adolescent girls in both the areas supported FP method use. Husbands' of the married adolescent girls in the intervention areas were more supportive (98.4\%) as compared to their comparison counterparts (91.2\%) (Table 6).

Table 6: Respondents' knowledge and perception on early marriage, early pregnancy, and birth spacing by intervention and comparison areas

\begin{tabular}{|c|c|c|c|}
\hline \multirow[b]{2}{*}{ Characteristics } & \multicolumn{2}{|c|}{ Married adolescent girls (\%) } & \multirow[t]{2}{*}{$P$ value } \\
\hline & $\begin{array}{c}\text { Intervention } \\
(n=799)\end{array}$ & $\begin{array}{c}\text { Comparison } \\
(n=802)\end{array}$ & \\
\hline \multicolumn{4}{|c|}{ Ideal age at marriage for a female (in years) } \\
\hline$<18$ & 1.3 & 1.0 & \\
\hline$\geq 18$ & 98.6 & 98.9 & \\
\hline Don't know & 0.1 & 0.1 & \\
\hline \multicolumn{4}{|c|}{ Ideal age at first childbirth for a female (in years) } \\
\hline$<18$ & 0.1 & 0.0 & \\
\hline$\geq 18$ & 99.9 & 98.4 & \\
\hline Don't know & 0.0 & 1.6 & \\
\hline \multicolumn{4}{|c|}{ Ideal time interval between two pregnancies (in years) } \\
\hline$\leq 2$ & 2.0 & 4.8 & \\
\hline $3-5$ & 25.7 & 20.6 & \\
\hline$>5$ & 72.3 & 74.6 & 0.001 \\
\hline \multicolumn{4}{|c|}{ Support FP method use } \\
\hline Yes & 99.1 & 94.7 & \\
\hline No & 0.9 & 4.5 & \\
\hline No opinion & 0.0 & 0.8 & \\
\hline \multicolumn{4}{|c|}{ Husbands support FP method use } \\
\hline Yes & 98.4 & 91.2 & \\
\hline No & 1.4 & 4.8 & \\
\hline Don't know & 0.2 & 4.0 & \\
\hline
\end{tabular}


Findings from the qualitative interviews showed that most of the respondents have learned about appropriate age at marriage, age at first birth for both girls and boys from the club sessions which have made them more aware about early marriage, early pregnancy and their adverse effects on mother and baby's health. One of the married adolescent girls quoted,

"...learned a lot and cleared the misconceptions about family planning method use. Also came to know about appropriate age of marriage and appropriate age of child bearing for both female and male"... (Age-17, Education-class 7, Occupation- Garments worker)

\section{Family planning method practices}

Almost all the married adolescent girls knew about any FP methods both in intervention and comparison areas. Ever use of any FP methods in their lifetime were found higher in the intervention areas $(93.7 \%)$ compared to the comparison areas (88.4\%). Respondents from the intervention areas were using more modern FP methods (72.6\%) than that of the comparison areas (63.2\%).

Respondents from the comparison group commonly used oral pill (43.8\%) as compared to the intervention areas (36.1\%). Use of other modern FP methods including injectable ( $35.0 \%$ vs $29.6 \%)$, condom ( $18.0 \%$ vs $15.6 \%)$, implant ( $5.6 \%$ vs $3.1 \%)$, and IUD ( $2.2 \%$ vs $1.3 \%)$, were being used more in the intervention areas as compared to the comparison areas respectively. More than three-fourths of the married adolescent girls both in the intervention and comparison areas wanted to have birth spacing for at least 2 years (Table 7).

Table 7: Family planning method practice among respondents by intervention and comparison areas

\begin{tabular}{|c|c|c|c|}
\hline \multirow[b]{2}{*}{ Characteristics } & \multicolumn{2}{|c|}{ Married adolescent girls (\%) } & \multirow{2}{*}{$\begin{array}{c}P \\
\text { value }\end{array}$} \\
\hline & $\begin{array}{l}\text { Intervention } \\
(n=799)\end{array}$ & $\begin{array}{c}\text { Comparison } \\
(n=802)\end{array}$ & \\
\hline \multicolumn{4}{|l|}{ Knew about any FP methods } \\
\hline Yes & 100.0 & 99.5 & \\
\hline No & 0.0 & 0.5 & \\
\hline \multicolumn{4}{|l|}{ Ever used FP methods } \\
\hline Yes & 93.7 & 88.4 & \\
\hline No & 6.3 & 11.6 & 0.000 \\
\hline Current use of any FP method & $n=749$ & $n=709$ & \\
\hline Modern contraceptive method & 72.6 & 63.2 & \\
\hline Traditional method & 1.7 & 4.2 & \\
\hline Not using any methods currently & 15.1 & 17.1 & \\
\hline Not applicable/currently Pregnant & 10.6 & 15.2 & 0.000 \\
\hline Types of FP methods used currently & $n=557$ & $n=480$ & \\
\hline Pill & 36.1 & 43.8 & 0.009 \\
\hline Injectable & 29.6 & 29.6 & 0.087 \\
\hline Condom & 18.0 & 15.6 & 0.393 \\
\hline Norplant & 5.6 & 3.1 & 0.051 \\
\hline IUD & 2.2 & 1.3 & 0.275 \\
\hline Male sterilization & 0.7 & 0.2 & 0.240 \\
\hline Female sterilization & 0.2 & 0.2 & 1.000 \\
\hline
\end{tabular}




\begin{tabular}{|c|c|c|c|}
\hline \multirow[b]{2}{*}{ Characteristics } & \multicolumn{2}{|c|}{ Married adolescent girls (\%) } & \multirow{2}{*}{$\begin{array}{c}P \\
\text { value }\end{array}$} \\
\hline & $\begin{array}{l}\text { Intervention } \\
(n=799)\end{array}$ & $\begin{array}{l}\text { Comparison } \\
(n=802)\end{array}$ & \\
\hline Withdrawal & 2.2 & 4.8 & 0.021 \\
\hline Periodic abstinence & 0.2 & 1.5 & 0.542 \\
\hline Wanted to have a child within 2 years & $n=799$ & $n=802$ & \\
\hline Yes & 11.9 & 16.3 & \\
\hline No & 86.0 & 81.1 & \\
\hline Not sure & 1.5 & 2.4 & \\
\hline Received permanent FP method & 0.6 & 0.2 & \\
\hline
\end{tabular}

Qualitative findings explored that the married adolescent girls have learned about different contraceptive methods, sources of contraceptive methods, comprehensive information on proper and consistent use of short term contraceptive methods, uptake of LARC, importance of birth spacing and limiting etc. from club sessions. According to one of the married adolescent girls -

"... I have learned many things about how to keep a family small and happy. I have decided that I will not make a large family. My husband does not have much wealth; our living depends on his earning. If my family extends, we will have to face problem to feed our children; we would not be able to take any medical facilities, if needed...how to keep a family small, how to maintain life, how to keep my child healthy...all these things I have learned from the club. So, now I will keep my family small, and will not take 4-5 children." (Age-15, Education-class 6, Occupation- Housewife)

\section{Spousal communication}

Married adolescent girls in the intervention areas discussed FP methods with their husbands more $(97.5 \%)$ compared to their counterparts at the comparison areas (84.7\%). Nearly one-third of the couples from the intervention areas discussed about FP methods during the day of their marriage whereas only $17.1 \%$ of the couples from the comparison areas did so. Two-thirds of the respondents from the intervention areas initiated the discussion by themselves whereas the prevalence was significantly less $(56.3 \%)$ in the comparison areas. Around three-fourth of the respondents from the intervention areas thought that both husband and wife should have the responsibility of using FP methods, which was found much lower (45.9\%) in the comparison areas (Table 8 ). 
Table 8: Spousal communication among respondents by intervention and comparison areas

\begin{tabular}{|l|c|c|c|}
\hline \multirow{2}{*}{ Characteristics } & \multicolumn{2}{|c|}{ Married adolescent girls (\%) } & P \\
\cline { 2 - 3 } & $\begin{array}{c}\text { Intervention } \\
(\mathrm{n}=799)\end{array}$ & $\begin{array}{c}\text { Comparison } \\
(\mathrm{n}=802)\end{array}$ & \\
\hline \multicolumn{2}{|l|}{} & & \\
\hline The couples ever discussed about FP method & 97.5 & 84.7 & \\
\hline Yes & 2.5 & 15.3 & 0.000 \\
\hline No & $\mathrm{n}=779$ & $\mathrm{n}=679$ & \\
\hline First time the couples talked about FP & 69.5 & 82.5 & \\
\hline Within 7 days of marriage & 30.2 & 17.1 & \\
\hline On the day of marriage & 0.4 & 0.4 & 0.000 \\
\hline Before marriage & & & \\
\hline Discussion initiated by whom & 66.9 & 56.3 & \\
\hline Respondents & 33.1 & 43.7 & 0.000 \\
\hline Respondents' husbands & $\mathrm{n}=799$ & $\mathrm{n}=802$ & \\
\hline $\begin{array}{l}\text { Responsibility of thinking and taking decision of } \\
\text { FP method use }\end{array}$ & 17.4 & 34.0 & \\
\hline Respondents' responsibility & 9.9 & 20.1 & \\
\hline Respondents' husband's responsibility & 72.7 & 45.9 & 0.000 \\
\hline Responsibility of both & & & \\
\hline
\end{tabular}

From qualitative exploration, a remarkable change was observed among husbands' participation in family planning through exchanging and sharing family planning related knowledge with their wives. More husbands were using contraceptive methods at the time of data collection and also discussed their active role in family planning related decision making with their wives, especially, in choosing FP methods and limiting births. One of the husbands stated that,

"My wife's current pregnancy suddenly happened... after the birth of this baby, we will have two children. We thought not to have more children after the second one.... whether it is a boy or girl, we do not want any more children" (Age-29, Education- no schooling, Occupation- Business)

\section{Knowledge on potential consequences of early pregnancy}

The respondents from the intervention areas gained more knowledge on consequences of early pregnancy that included, possibility of antenatal complications ( $94.2 \%$ vs $84.8 \%)$, spontaneous abortions ( $12.9 \%$ vs $2.0 \%)$, maternal deaths $(50.7 \%$ vs $39.3 \%)$, new-born complications $(77.5 \%$ vs $30.2 \%)$, perinatal/ neonatal deaths ( $35.3 \%$ vs $27.7 \%$ ) as compared to the comparison areas respectively (Table 9). 
Table 9: Respondents' knowledge on potential consequences of early pregnancy by intervention and comparison areas

\begin{tabular}{|l|c|c|c|}
\hline \multirow{2}{*}{ Characteristics } & \multicolumn{2}{|c|}{ Married adolescent girls (\%) } & \\
\cline { 2 - 4 } & $\begin{array}{c}\text { Intervention } \\
(\mathrm{n}=799)\end{array}$ & $\begin{array}{c}\text { Comparison } \\
(\mathrm{n}=802)\end{array}$ & $\mathrm{P}$ value \\
\hline Potential consequences of early pregnancy & \multicolumn{2}{|l|}{} \\
\hline Chances of risk during pregnancy & 94.2 & 84.8 & 0.000 \\
\hline Baby/new-born may be at risk & 77.5 & 30.2 & 0.000 \\
\hline Mother may die & 50.7 & 39.3 & 0.000 \\
\hline Baby may die & 35.3 & 27.7 & 0.001 \\
\hline Chances of having C/S delivery & 13.1 & 20.1 & 0.000 \\
\hline Chances of having spontaneous abortion & 12.9 & 2.0 & 0.000 \\
\hline May need to leave job & 3.1 & 0.5 & 0.000 \\
\hline Education may be stopped & 1.9 & 0.9 & 0.084 \\
\hline
\end{tabular}

\section{Unintended pregnancy}

Among all, $22.0 \%$ of the respondents from the intervention areas and $28.5 \%$ from the comparison areas were pregnant during the time of interview or delivered in the last three months prior to the interview. Among them, nearly one-half of the respondents from both the areas $(47.2 \%$ in the intervention and $48.0 \%$ in the comparison areas) reported their last/current pregnancy as an unintended pregnancy (Table 10).

Table 10: Pregnancy intention (last/current) of respondents by intervention and comparison areas

\begin{tabular}{|l|c|c|l|}
\hline \multirow{2}{*}{ Characteristics } & \multicolumn{2}{|c|}{ Married adolescent girls (\%) } & $\begin{array}{l}p \\
\text { value }\end{array}$ \\
\cline { 2 - 3 } & $\begin{array}{c}\text { Intervention } \\
(\mathrm{n}=176)\end{array}$ & $\begin{array}{c}\text { Comparison } \\
(\mathrm{n}=229)\end{array}$ & \\
\hline Wanted & 52.8 & 52.0 & \\
\hline Wanted later (mistimed) & 46.0 & 47.1 & \\
\hline Not wanted at all (unwanted) & 1.2 & 0.9 & \\
\hline
\end{tabular}

Significant variations were found regarding the reasons of unintended pregnancy among respondents between the intervention and comparison areas. These included, forgot to use a method ( $43.3 \%$ vs $56.7 \%$ ), reluctant to use any FP method ( $56.8 \%$ vs $43.2 \%$ ), unaware of any FP method ( $45.5 \%$ vs $54.5 \%$ ), unavailability of FP method (33.3\% vs $66.7 \%)$, to fulfil husband's desire $(22.2 \%$ vs $77.8 \%)$, mother-in-laws' desire ( $25.0 \%$ vs $75.0 \%$ ), fear of side effects of methods ( $60.0 \%$ vs. $40.0 \%$ ), lack of access to obtain the method (50.0\% vs $50.0 \%$ ), and superstition (20.0\% vs. $80.0 \%)$ (Figure 4 ). 
Figure 4: Percent distribution of respondents by major causes of unintended pregnancy by intervention and the comparison areas

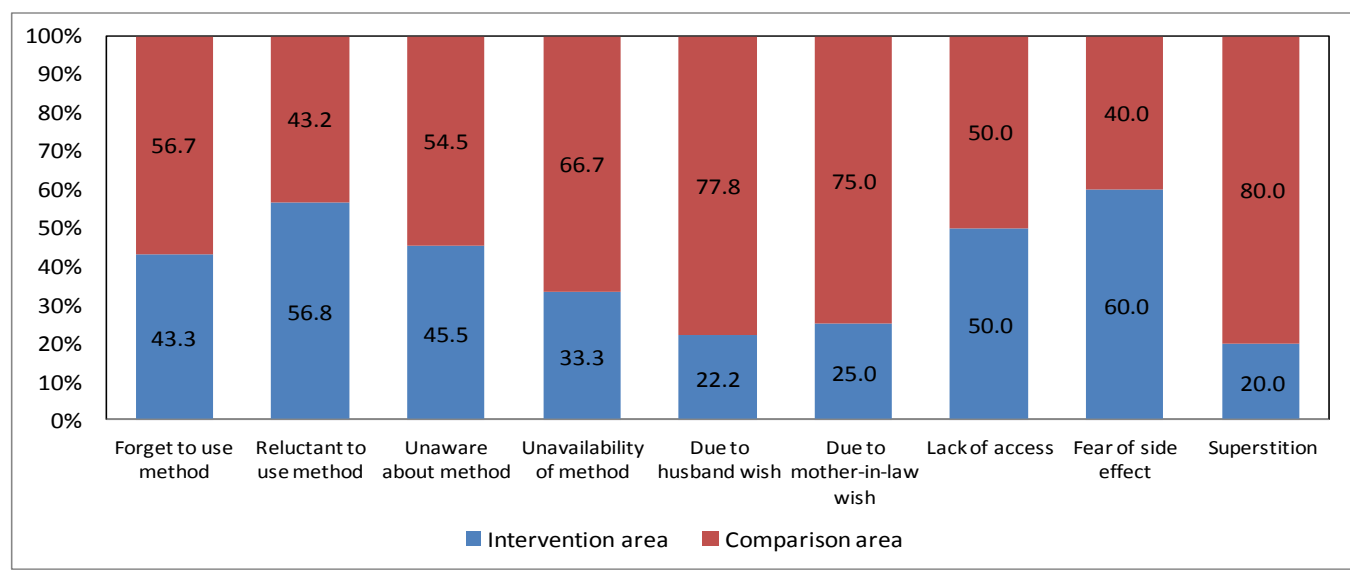

Findings from the qualitative interviews explored that after receiving FP related information from the club sessions, most of the married adolescent girls' were able to place strong opinion in choosing and using FP methods to their husbands, and their negotiation skill regarding those discussion with their husbands' were also increased. One of married adolescent girls credited her participation in club with following quote:

"I had two consecutive MR (menstrual regulation) within six months because my husband did not want the babies. I had to follow his order as he is the only breadwinner of the family. But I had suffered a lot both physically, mentally, and economically......then I talked with Apa (icddr,b field team member) and she invited me to attend the married adolescent girls' club session. I joined the club with the thought that I will learn many things from there. And that was true now I am able to discuss family planning issues (which is good, which is bad) with my husband........and finally I was able to receive 'Implant' to delay my next pregnancy" (Age-

\section{9, Education-class 06, Occupation- Housewife)}

Knowledge on delayed pregnancy, birth spacing, and birth limiting also influenced the married adolescent girls profoundly; especially those, who were married for one year ( 3 of the respondents) and had not any child, had planned to delay their first pregnancies at least for three to five years. The major factors that influenced them to delay first pregnancy were to attain economical solvency and physical capability/fitness to bear a child. They already had started using convenient methods at the time of data collection.

Among the respondents, who already had a child within one year of their marriage showed their preference in receiving anyone of the long acting reversible contraceptive (LARC) methods for giving 
space for the next pregnancy. Six of the married adolescent girls had thought about limiting their child birth. At the time of conducting interview, married adolescent girls, who were found pregnant (3) or in lactational amenoerrheic period (1) had planned to use a suitable contraceptive method after their child birth and/or after initiation of their regular period. One of the respondents with unintended pregnancy told:

"I got married at an early age, if I knew about various contraceptive methods that are available for preventing birth, I would use them..." (Age-14, Education- no schooling, OccupationHousewife)"

Eight of the respondents who received LARC showed strong motivation in selecting a long-term method for birth spacing, and they acknowledged the positive impact of the club sessions in their life that had helped them in gathering detailed knowledge and information about LARC, and also had communicated them with the Shyastha Shebikas, who had assisted them in obtaining the method.

\section{Unmet need for family planning}

Married adolescent girls who were not pregnant at the time of the survey, wanted to delay the next birth by two or more years but were not using any family planning methods were considered to have unmet need for family planning. There was a significant difference among the respondents between the intervention and comparison areas that had an unmet need for FP (16.2\% vs. $20.7 \%)$.

Significant variation was also observed among the respondents of both the areas who had an unmet need for FP by their socio-demographic characteristics. Unmet need for FP was significantly higher among the respondents of aged 18 years and above (19.0\%) from the comparison areas as compared to the intervention areas (13.7\%). Though employment status of the married adolescent girls was not significantly different for unmet need for FP, but among the respondents who were garments workers had a significant difference between the intervention and comparison areas ( $5.7 \%$ vs. $20.0 \%$ ) for having an unmet need for FP. The unmet need was significantly lower among the respondents with love marriage from the intervention areas (13.8\%) as compared to the comparison areas $(20.5 \%)$. In addition, the married couples of the intervention areas who stayed together had significantly lower unmet need for FP (12.6\%) as compared to the comparison areas (17.9\%) (Table 11). 
Table 11: Percent distribution of respondents' unmet need for FP by socio-demographic characteristics and by intervention and comparison areas

\begin{tabular}{|c|c|c|c|c|c|}
\hline \multirow[t]{3}{*}{ Characteristics } & \multicolumn{4}{|c|}{ Married adolescent girls (\%) } & \multirow[t]{3}{*}{$p$-value } \\
\hline & \multicolumn{2}{|c|}{ Intervention } & \multicolumn{2}{|c|}{ Comparison } & \\
\hline & $\begin{array}{l}\text { Number of } \\
\text { respondents }\end{array}$ & $\begin{array}{c}\text { Unmet } \\
\text { need }\end{array}$ & $\begin{array}{l}\text { Number of } \\
\text { respondents }\end{array}$ & $\begin{array}{c}\text { Unmet } \\
\text { need }\end{array}$ & \\
\hline \multicolumn{6}{|l|}{ Study area } \\
\hline Kamrangirchar & 399 & 17.8 & & & \\
\hline Mirpur & 400 & 14.5 & & & \\
\hline Rayerbazar & & & 402 & 22.1 & \\
\hline Shekhertek & & & 400 & 19.3 & \\
\hline Total & 799 & 16.2 & 802 & 20.7 & 0.019 \\
\hline \multicolumn{6}{|c|}{ Age of respondents (in years) } \\
\hline$\leq 15$ & 27 & 29.6 & 45 & 22.2 & 0.482 \\
\hline $16-17$ & 187 & 21.9 & 168 & 26.2 & 0.347 \\
\hline$\geq 18$ & 585 & 13.7 & 589 & 19.0 & 0.013 \\
\hline \multicolumn{6}{|c|}{ Education of respondents (in years) } \\
\hline No education & 111 & 22.5 & 86 & 22.1 & 0.943 \\
\hline $1-5$ & 323 & 15.2 & 330 & 22.7 & 0.014 \\
\hline $6-8$ & 255 & 14.1 & 232 & 20.3 & 0.072 \\
\hline $9+$ & 110 & 17.3 & 154 & 16.2 & 0.823 \\
\hline \multicolumn{6}{|c|}{ Employment status of respondents } \\
\hline Employed & 258 & 13.6 & 119 & 16.0 & 0.536 \\
\hline Not employed & 541 & 17.4 & 683 & 21.5 & 0.070 \\
\hline \multicolumn{6}{|c|}{ Types of employment of respondents } \\
\hline Handicrafts & 134 & 14.9 & 13 & 15.4 & 0.965 \\
\hline Garments/factory worker & 53 & 5.7 & 30 & 20.0 & 0.044 \\
\hline Others & 44 & 11.4 & 27 & 7.4 & 0.587 \\
\hline Maid servant & 27 & 25.9 & 49 & 18.4 & 0.439 \\
\hline \multicolumn{6}{|c|}{ Age at marriage of respondents (in years) } \\
\hline$\leq 14$ & 383 & 13.3 & 277 & 14.1 & 0.778 \\
\hline $15-17$ & 391 & 19.2 & 445 & 23.2 & 0.162 \\
\hline$\geq 18$ & 25 & 12.0 & 80 & 30.0 & 0.072 \\
\hline \multicolumn{6}{|c|}{ Types of marriage of respondents } \\
\hline Love marriage & 412 & 13.8 & 473 & 20.5 & 0.009 \\
\hline Arranged marriage & 387 & 18.6 & 329 & 21.0 & 0.427 \\
\hline \multicolumn{6}{|c|}{ Agreement on arranged marriage } \\
\hline Yes & 378 & 14.3 & 445 & 20.5 & 0.021 \\
\hline No & 34 & 8.8 & 28 & 21.4 & 0.161 \\
\hline \multicolumn{6}{|c|}{ Husband stays with respondents } \\
\hline Regularly & 729 & 12.6 & 753 & 17.9 & 0.005 \\
\hline Irregularly & 70 & 52.9 & 49 & 63.3 & 0.259 \\
\hline
\end{tabular}




\section{CONCLUSION}

This was an intervention study conducted among the married adolescent girls aged 15-19 years resided in four urban slums of Dhaka city of Bangladesh. Objectives of the study was to examine the acceptability and feasibility of forming married adolescent girls' clubs, and involving brac Shasthya Shebikas and marriage registrars to increase access to family planning information and services, to promote the uptake of long-acting reversible contraceptive (LARC) methods, and to provide FP information to the newly wed couples at the time of marriage registration. Ultimate goal of the study was to see the effectiveness of the individual intervention component as well as assessment of the combined effect of all three interventions in reducing unmet need for family planning and unintended pregnancy among the target population.

Major findings demonstrated the married adolescent girls' ability to receive family planning information through participating in the clubs and communication with the brac Shyastha Shebikas'. An enhanced knowledge on unintended pregnancy and on family planning issues was observed among the married adolescent girls, their husbands' and in the community. The evaluation result of the study indicates an increased number of married adolescent girls were using family planning methods, as well as conducting discussion on family planning with their husbands.

Findings from the study showed that the married adolescent girls' clubs empowered the respondents with the rare opportunity to assemble in a common platform to socialize and to share their experiences and challenges related to early marriage, early pregnancy, unintended pregnancy- their cause, consequences, and family planning information and services. A knowledge linkage was also established between club participants and their peers who did not get the opportunity of attending the club sessions. The club participants offered more support, and encourage their peers who could not attend the clubs, to use family planning methods.

In Bangladesh, traditionally, male involvement is negligible in family planning issues such as, contraceptive method use, determining family size, birth spacing, and limiting birth. The married adolescent girls' clubs played an important role in providing a trusted space for the adolescent girls in developing negotiation skills with their partners, especially in choosing and using contraceptive methods. Many of the husbands' of the study respondents' showed greater interest in family planning related discussion and decision making process. Findings also showed that being a part of married adolescent girls' clubs, the respondents became more independent, which helped them to bring 
necessary positive life choices. Most of the respondents mentioned the value of learning about taking care of their children and the importance of birth spacing.

In addition to club activities, information related to unintended pregnancy - their reasons and consequences, benefits of using family planning methods, their side effects, birth planning, spacing and male participation in family planning were also disseminated through Shasthya Shebikas. Findings from the study revealed that Shyastha Shebikas were useful in increasing short and long acting contraceptive method uptake, in understanding the importance of birth spacing, and in limiting birth among the married adolescent girls.

During the intervention period, a growing interest was observed among the respondents in family planning related decision making and method choices and many of them willingly received FP methods in order to prevent unintended pregnancy. The Shyastha Shebikas roles were also found helpful in facilitating the married adolescent girls' attendance in club sessions, and referring and accompanying interested girls' for long-acting reversible contraceptives (LARC) to family planning service centres which showed increased long acting method uptake during the project period.

The marriage registrars' effort in family planning information dissemination and counselling the newlywed couples regarding the FP issues was not found significant. A limited number of newlywed couples could receive FP related knowledge from the pocketbook distributed by the marriage registrars. Two of the married adolescent girls, who were identified from the registry book of the marriage registrars and interviewed in-depth, indicated minimum effects of pocketbooks in their married life because they had received the pocket book around ten days after their marriage, and due to this delay, they could not avail the FP information/services when they were in need.

Similar concern was observed on the perspectives of the marriage registrars as well - they found it difficult getting the newlywed couples at a separate/private place, apart from the guests attending the ceremony; therefore distributing the pocket book immediately after marriage registration was not feasible sometime. In some cases, explaining the messages/contents of the pocket book explicitly in front of many guests was embarrassing to both the parties. Also marriage brings new involvements and responsibilities that often did not allow the newlywed couples to read the pocket book together. Kazis mentioned that during collecting the duplicate copy of marriage registration document (Nokol Nikah Nama), the couple or their family members usually come to their office one month after marriage registration. According to them, it could be declared mandatory for the newlywed couples (only the 
husband and the wife) to visit the Kazi office to collect the Nokol Nikah Nama, so that the Kazis' get an opportunity of delivering the FP pocket book and its messages to them exclusively.

Contrasting with the other two intervention components, though the marriage registrars had faced more challenges to reach the study goals, but they did not take their involvement in the project as added responsibilities rather considered as a duty and suggested continuing the activity for further duration. They mentioned that, Kazis were recruited from local community and everybody in the society respects them. People used to meet them during marriage or divorce but they are always ready to be a part of this kind of initiative for the national interest in future also. Some people have misconceptions about family planning from their religious perspectives; the Kazis thought that they can also play a vital role in the community in this regards, because of their well acceptance in the society as a religious leader as well. They also thought that some charity activities such as, distributing warm clothes from the club venues during winter season to the married adolescent girls' and their families might help bringing more diversified people in a common platform where information dissemination regarding family planning issues could be initiated.

The study findings revealed that a noteworthy number of married adolescent girls had received FP related information mostly from the married adolescent girls' clubs and Shasthya Skebikas that had significant effects in their reproductive lives. It can be expected that the capability of the married adolescent girls that had been developed through the study interventions can assist them to overcome family planning and unintended pregnancy related knowledge and service gaps in the future. 


\section{LIMITATIONS}

The study was not without limitations:

- brac school venues were used for club session conduction and no separate club venues were formed/dedicated particularly for this intervention. Therefore, difficulties regarding availability of the venues, club session timing, and interior decoration were commonly raised during the entire intervention period.

- Because of more demand of the field implementation team's time in the married adolescent girls' club component, interaction with Shasthya Shebikas and follow up of their activities by the field implementation team was found inadequate.

- Couples from different places of the country came to the Kazi offices in the intervention areas for their marriage registration. Similarly, many couples from the intervention areas registered their marriage outside their place of residence; therefore, a larger part of this group was missed and was not included in the study. Additionally, Kazis were called and brought by the bride's family from their area of residence. By tradition, brides are usually moved to their husband's residence after marriage. Therefore, many of the married girls could not be traced at their natal home which ultimately caused lost to follow-up of a major portion. 


\section{RECOMMENDATIONS}

Despite a range of efforts, child marriage before age 18 and pregnancy rates before age 20 have not changed significantly for the poorest and least educated girls, and those who live in urban slums. Considering these major issues, this study lead to some recommendations:

1. Program planners and managers should identify and target the geographic 'hotspots' - areas with concentrations of girls at risk of child marriage and pregnancy, and their levels of satisfied demand for family planning information and services.

2. Married adolescent girls' health should be addressed as a national priority. Intense efforts in policy, legislation, program implementation, and research can exhibit the path to improved and more equitable access to family planning information and services for them.

3. Policy makers, program planners and implementers can use this evidence base by designing and implementing married adolescent-friendly programs that can address the demands created by the target group and promote a package of interventions to endorse utilization of services.

4. Birth and marriage registration systems should be strengthened to support the enforcement of child marriage laws. Strengthening and implementing laws on child marriage should be part of a national action plan, and greater efforts are needed to raise awareness at the community level to protect girls from child marriage.

5. Further analysis of the determinants of child marriage and pregnancies before age 18 (demographic, cultural, social and economic factors) should be done to better inform policies and programmes, and to strengthen the evidence base and programmatic linkages with education, health and poverty reduction.

6. To carry out the activities of married adolescent girls' clubs, Shasthya Shebikas, and marriage registrars - public-private partnership and involvement of key gatekeepers and stakeholders (such as in-laws, teachers, religious leaders, local level political leaders etc.) at the outset should be ensured.

7. For further scale up of the interventions, the target population needs to be involved from the beginning and in all aspects of programme design. Pre-testing of all messages for behavior change communication (BCC) is essential, and relevant supportive networking and training activities need to be carried out throughout the life of the project. 


\section{REFERENCES}

1. National Institute of Population Research and Training (NIPORT), Mitra and Associates, and ICF International. 2016. Bangladesh Demographic and Health Survey 2014. Dhaka, Bangladesh and Rockville, Maryland, USA: NIPORT, Mitra and Associates, and ICF International.

2. Santhya, K. (2011). Early marriage and sexual reproductive health vulnerabilities of young women: a synthesis of recent evidence from developing countries. Current Opinion in Obstetrics \& Gynecology. 23(5): 334-339.

3. Gipson, J., Koenig, M., \& Hindin, M. (2008). The Effects of Unintended Pregnancy on Infant, Child, and Parental Health: A Review of the Literature. Studies in Family Planning, 39(1): 18-38.

4. National Institute of Population Research and Training. (2008). 2006 Bangladesh Urban Health Survey. Dhaka, Bangladesh and Chapel Hill, NC, USA: NIPORT, MEASURE Evaluation, icddr,b, and ACPR.

5. Huda, F.A., Chowdhuri, S., Ahmed, A., \& Sarker, B.K. (2014). Prevalence of unintended pregnancy and need for family planning among married adolescent girls living in urban slums of Dhaka, Bangladesh. Dhaka: Centre for Reproductive Health/icddr,b.

6. Costed Implementation Plan for the National Family Planning Programme, Bangladesh; 20162020; Ministry of Health and Family Welfare (MOHFW), Bangladesh; Final report, 23 December 2015. 


\section{PHOTO GALLERY}
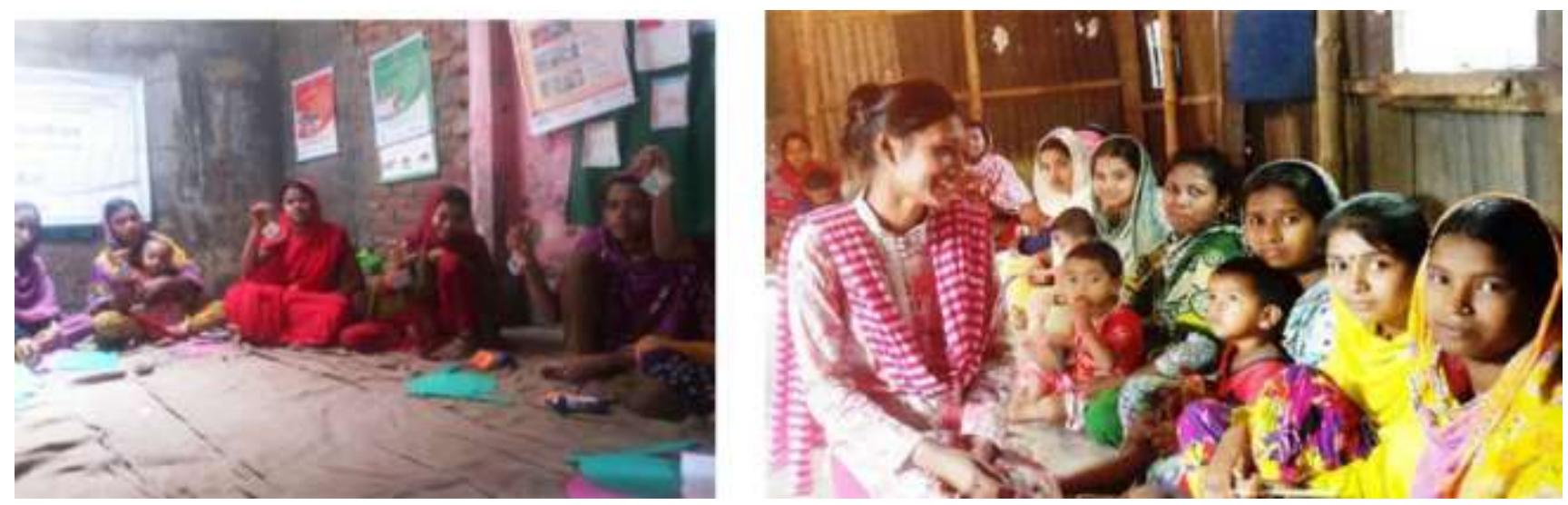

Married adolescent girls' club activities

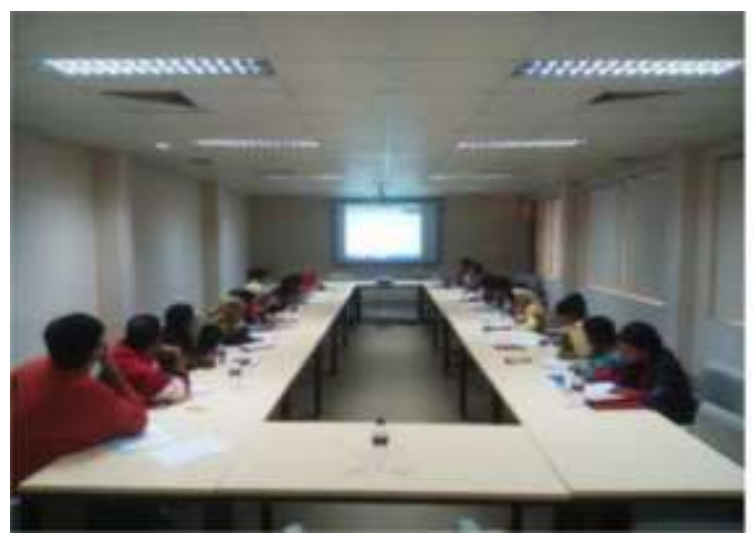

Drama script finalization meeting

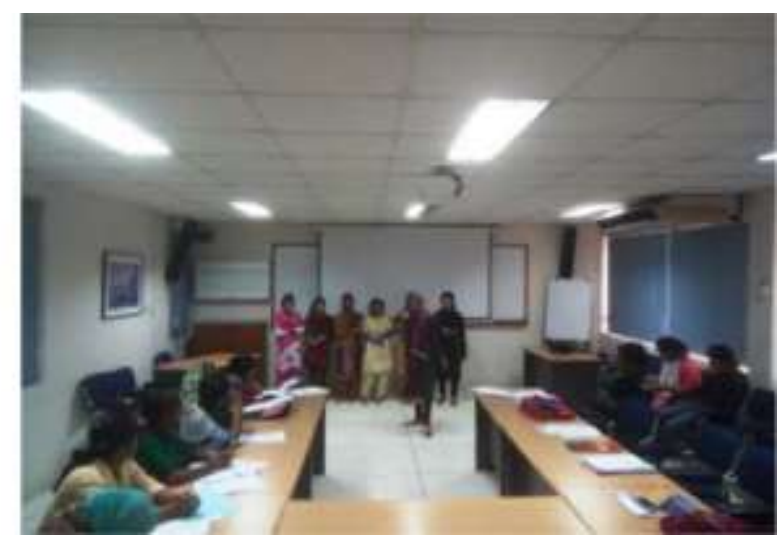

Drama rehearsal at icddr,b

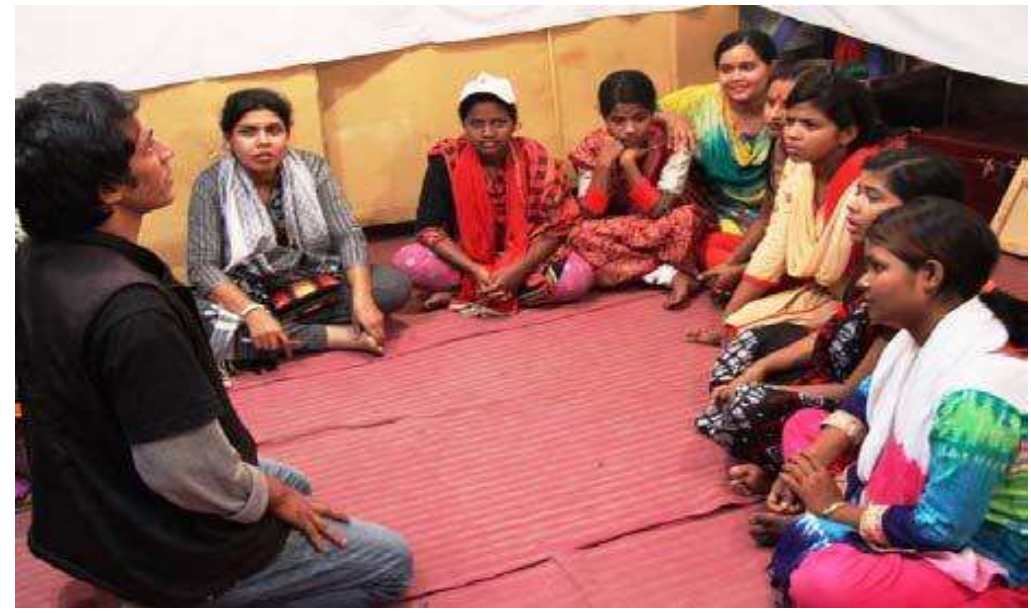

Drama rehearsal under the guidance of the Director 


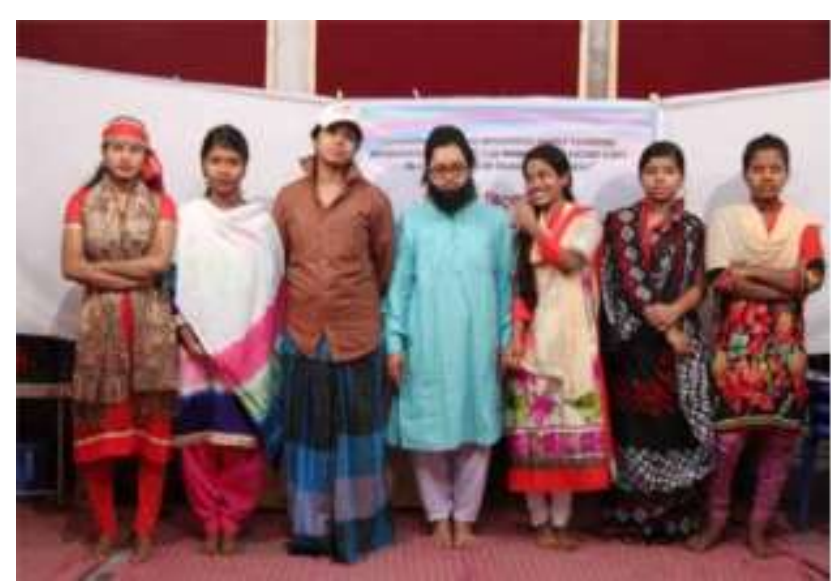

Drama team members (Kamrangirchor)

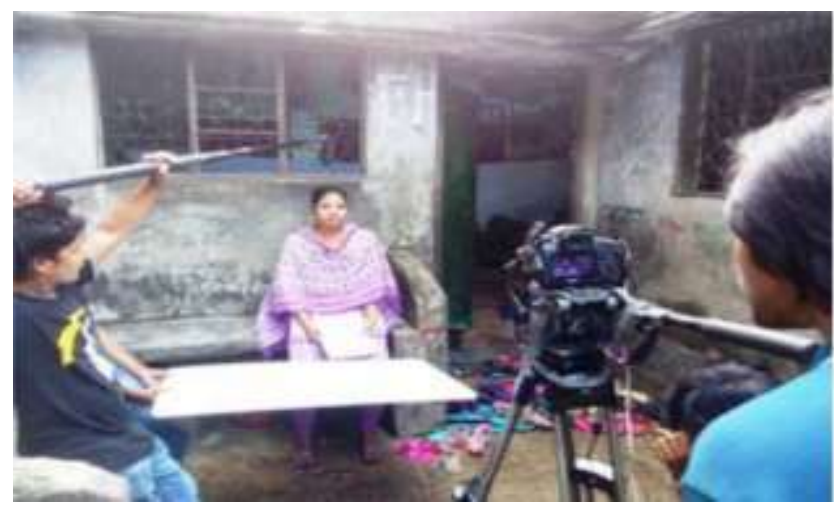

Shooting of documentary in Mirpur and Kamrangirchor

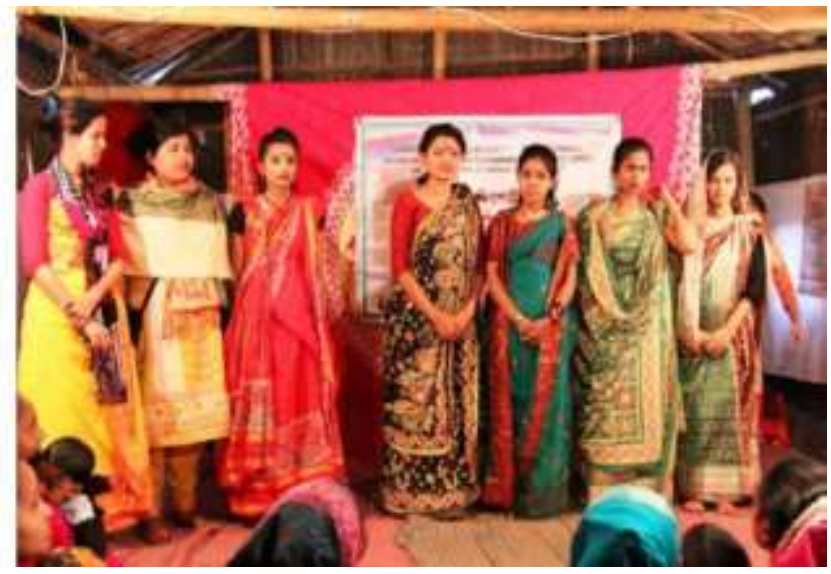

Drama team members (Mirpur)

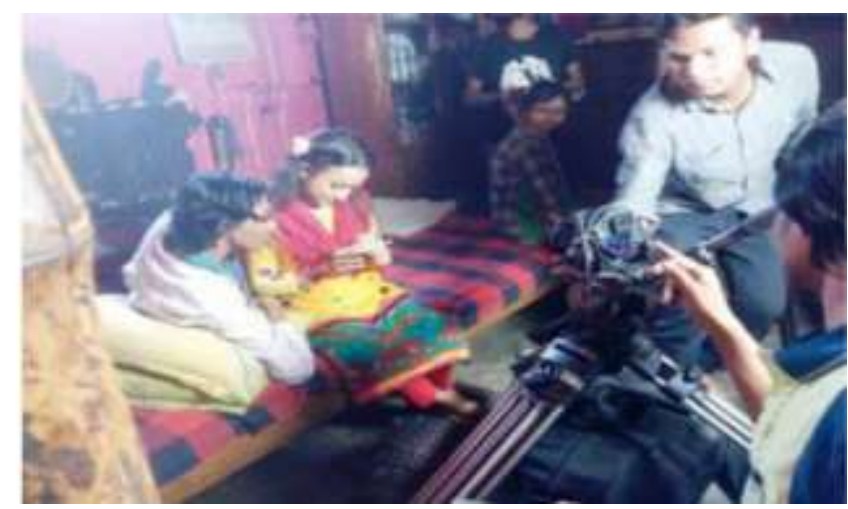




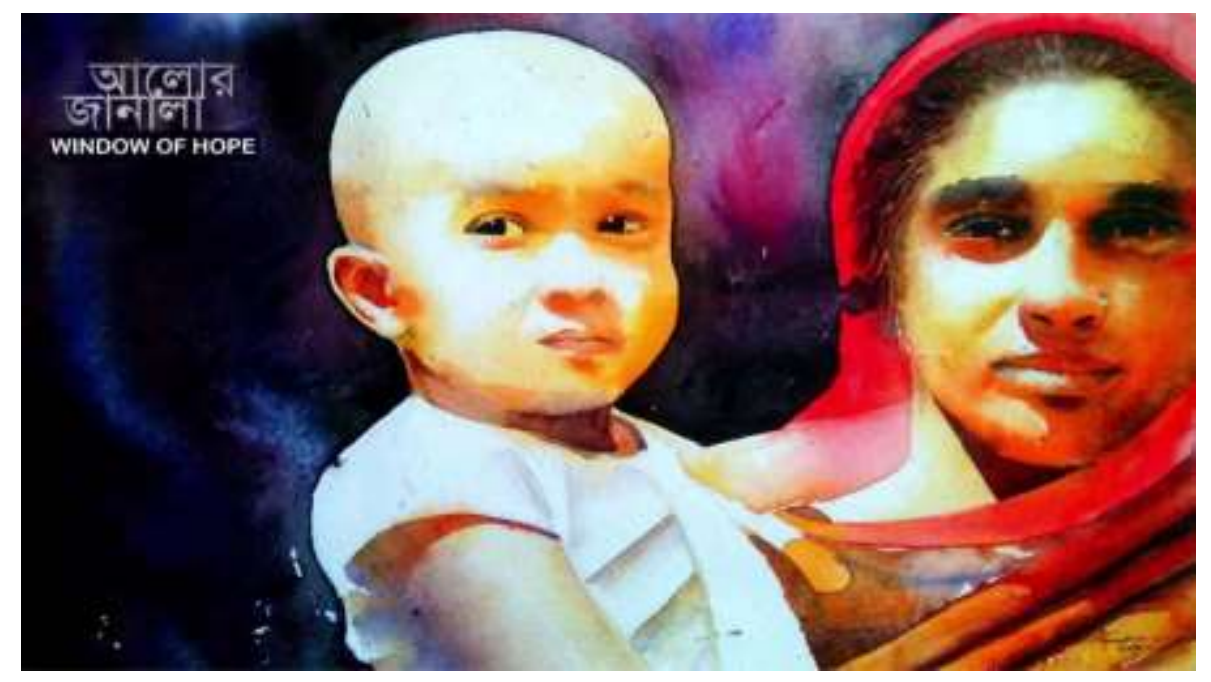

The story book: "Window of Hope"
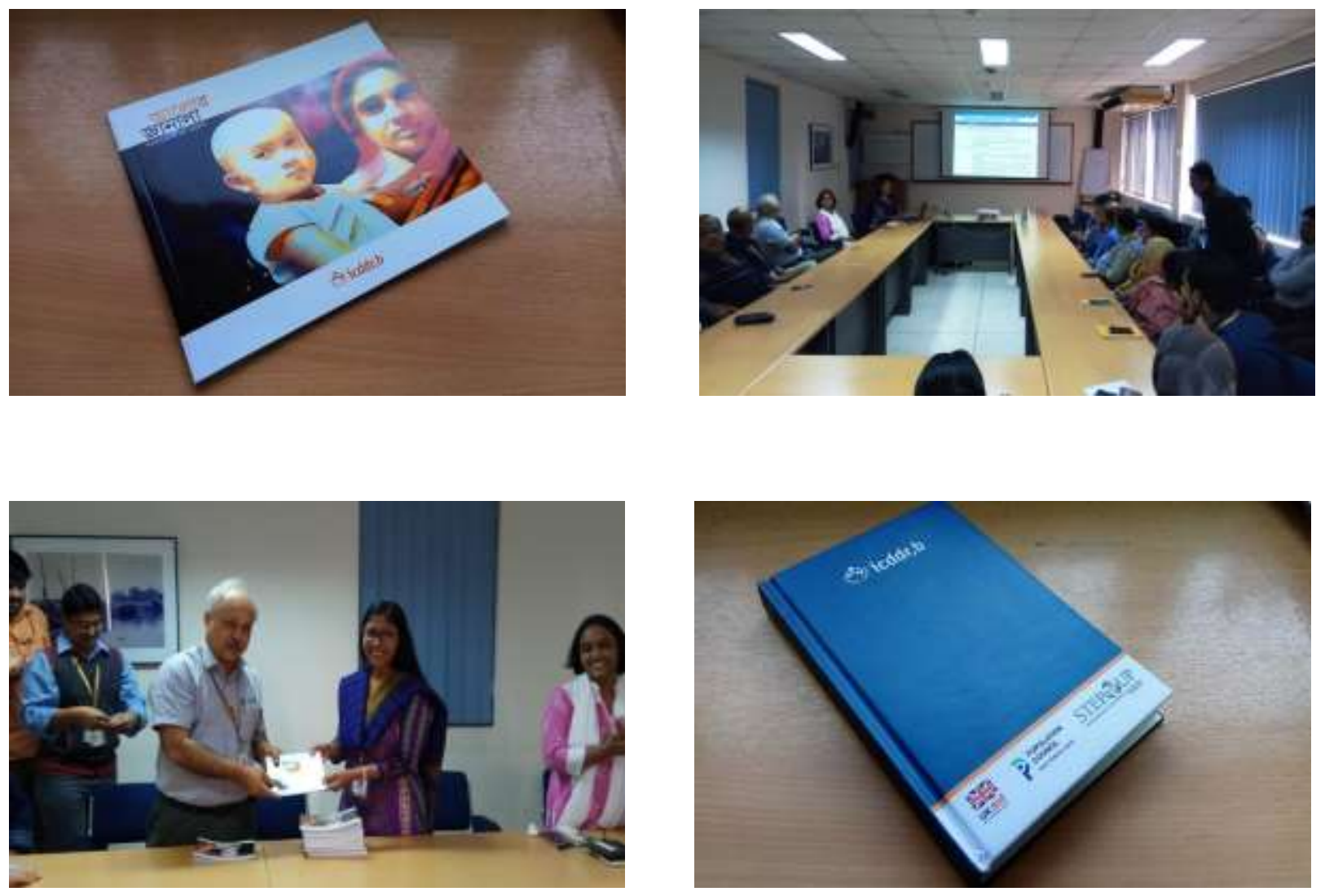

Launching program of the documentary and the storybook 


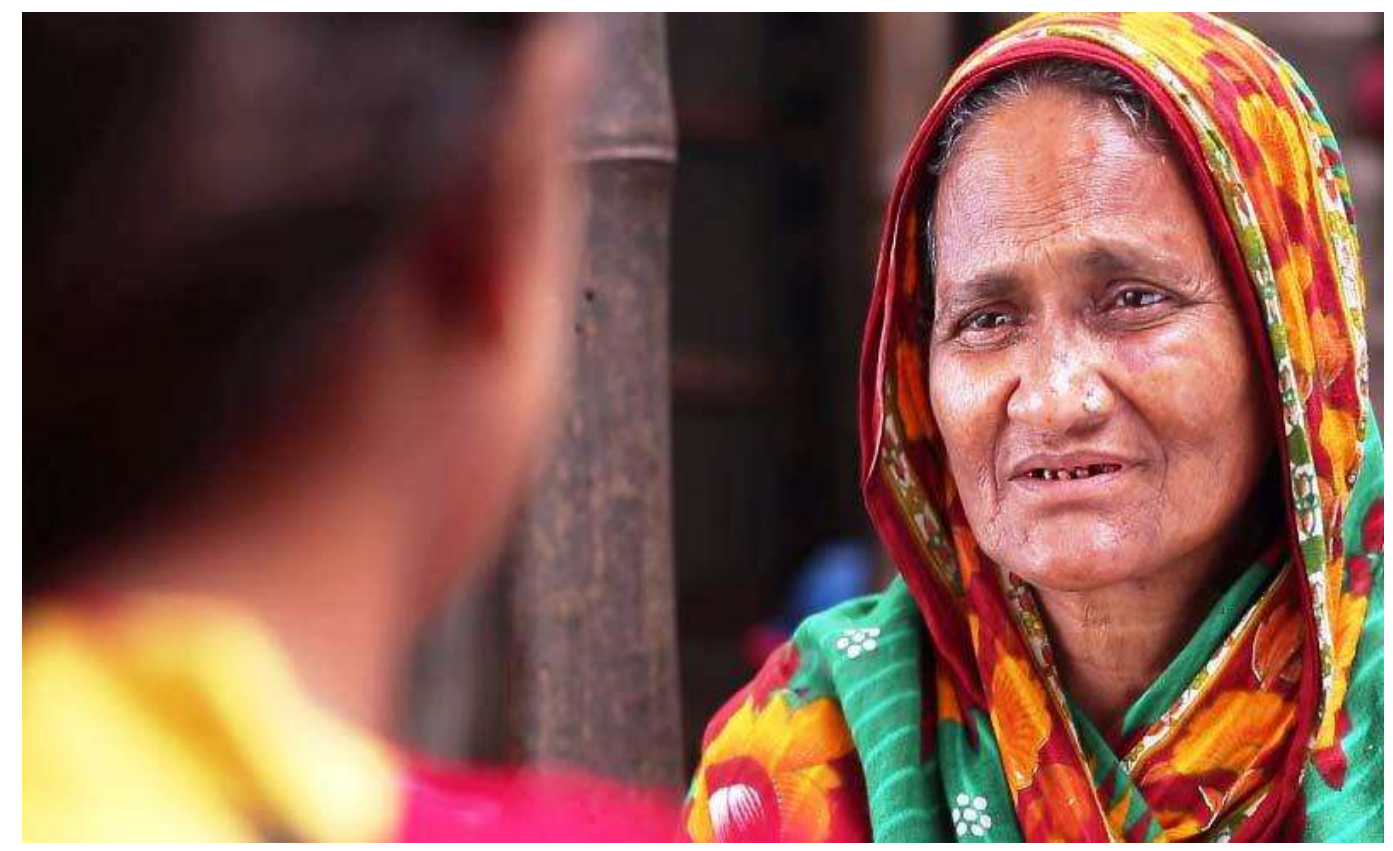

Household visit by brac Shyastha Shebika

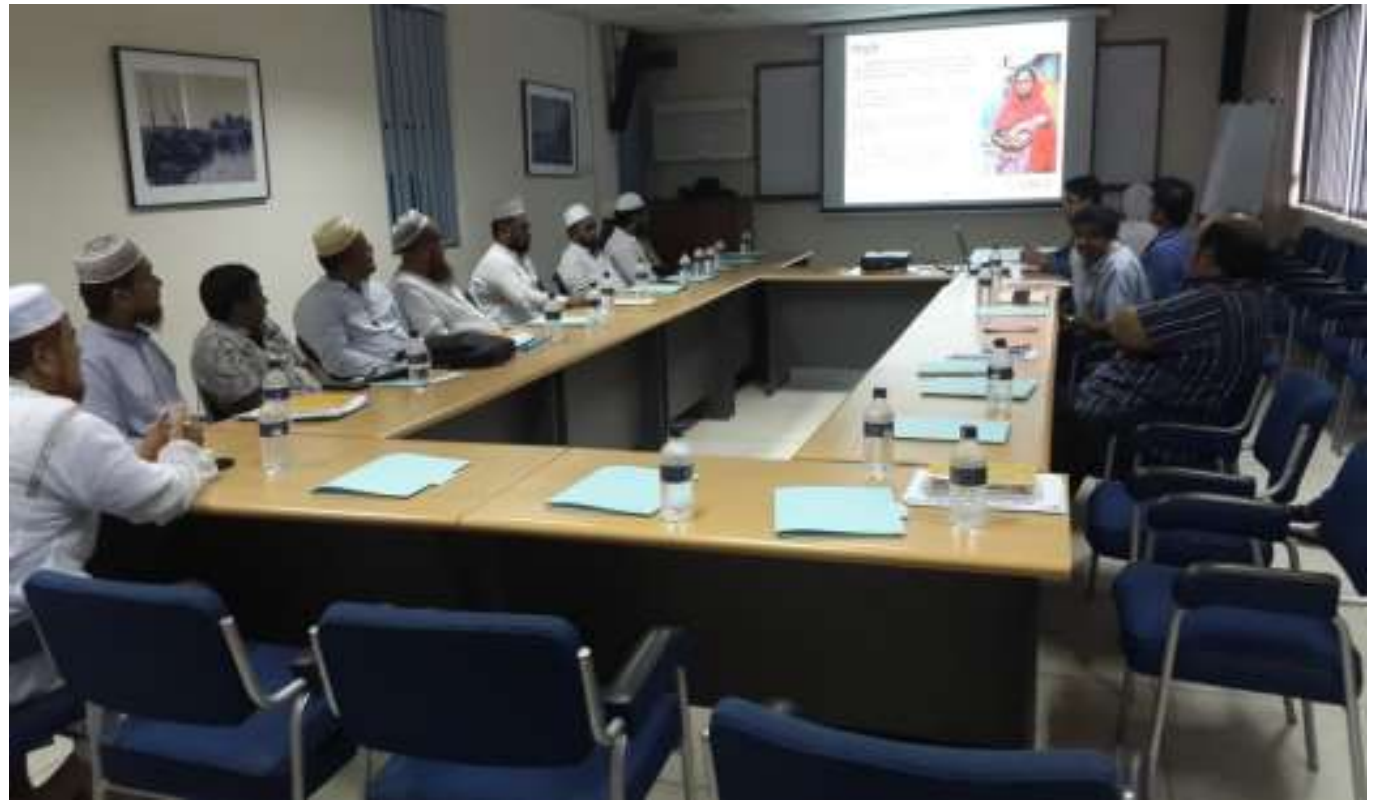

Training of the marriage registrars at icddr, $b$ 


\section{http://stepup.popcouncil.org}

The STEP UP (Strengthening Evidence for Programming on Unintended Pregnancy) Research Programme

Consortium generates policy-relevant research to promote an evidence-based approach for improving access to family

planning and safe abortion. STEP UP focuses its activities in

five countries: Bangladesh, Ghana, India, Kenya, and Senegal.

STEP UP is coordinated by the Population Council in partnership with the African Population and Health Research Center; icddr,b; the London School of Hygiene and Tropical Medicine; and Marie Stopes International. STEP UP is funded by UK aid from the UK Government. 